\title{
Attenuation of Spatial Memory Impairment in a Tau Mouse Model of Alzheimer's Disease with Riluzole
}

Daniel S. Weitzner

Follow this and additional works at: https://researchrepository.wvu.edu/etd

\section{Recommended Citation}

Weitzner, Daniel S., "Attenuation of Spatial Memory Impairment in a Tau Mouse Model of Alzheimer's Disease with Riluzole" (2015). Graduate Theses, Dissertations, and Problem Reports. 6935.

https://researchrepository.wvu.edu/etd/6935

This Thesis is protected by copyright and/or related rights. It has been brought to you by the The Research Repository @ WVU with permission from the rights-holder(s). You are free to use this Thesis in any way that is permitted by the copyright and related rights legislation that applies to your use. For other uses you must obtain permission from the rights-holder(s) directly, unless additional rights are indicated by a Creative Commons license in the record and/ or on the work itself. This Thesis has been accepted for inclusion in WVU Graduate Theses, Dissertations, and Problem Reports collection by an authorized administrator of The Research Repository @ WVU. For more information, please contact researchrepository@mail.wvu.edu. 
Attenuation of Spatial Memory Impairment in a

Tau Mouse Model of Alzheimer's Disease with Riluzole

Daniel S. Weitzner

Thesis submitted

To the Eberly College of Arts and Sciences

At West Virginia University

In partial fulfillment of the requirements for the degree of

Master of Science in

Psychology

\author{
Committee \\ Miranda Reed, Ph.D., Chair \\ Steven Kinsey, Ph.D. \\ Julie Hicks Patrick, Ph.D. \\ Department of Psychology
}

Morgantown, West Virginia

2015

Keywords: Alzheimer's disease, riluzole, tau, glutamate, spatial working memory 


\author{
ABSTRACT \\ Attenuation of Spatial Memory Impairment in a \\ Tau Mouse Model of Alzheimer's Disease with Riluzole
}

\title{
Daniel Weitzner
}

Individuals at risk for developing Alzheimer's disease (AD) often demonstrate hyperactivity in areas of the memory network, such as the hippocampus, prior to AD diagnosis. Evidence suggests that this hyperactivity might be a contributing factor to the development of $\mathrm{AD}$. Tau, a protein responsible for binding and maintaining microtubules, has been implicated as a factor in hyperactivity, potentially through its alterations in glutamate signaling. Glutamate, the primary excitatory neurotransmitter in the central nervous system, is essential for learning and memory. However, excess glutamate that accumulates in the synapse can lead to neuron loss and eventual behavioral impairments. Recently, our lab has found that a tau mouse model of AD (rTg(TauP301L)4510) exhibits an increase in glutamate release and a decrease in glutamate clearance, effects that are correlated with memory deficits. We hypothesized that regulating glutamate levels would attenuate the spatial memory deficits observed in TauP301L mice. To test this, we administered riluzole, an FDA-approved disease-modifying drug for the treatment of amyotrophic lateral sclerosis, which decreases glutamate release and increases glutamate uptake. TauP301L mice exhibited memory deficits in the 8-arm water radial arm maze (WRAM), and administration of riluzole attenuated these deficits. Our findings establish a potential therapeutic intervention for memory deficits caused by glutamate dysregulation. 
Table of Contents

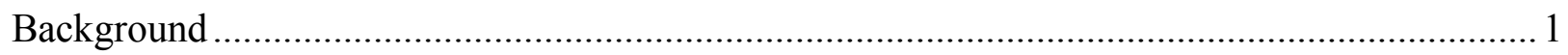

The Glutamate Life Cycle.................................................................................... 5

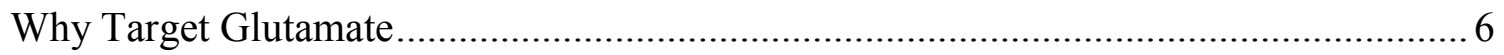

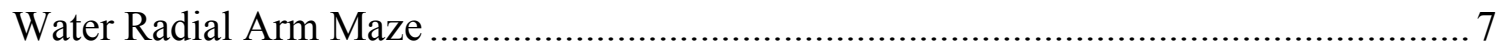

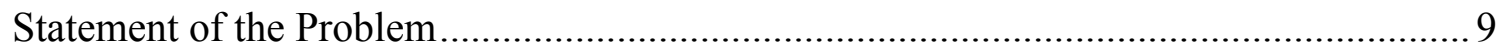

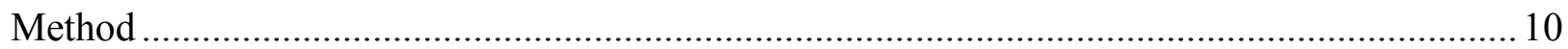

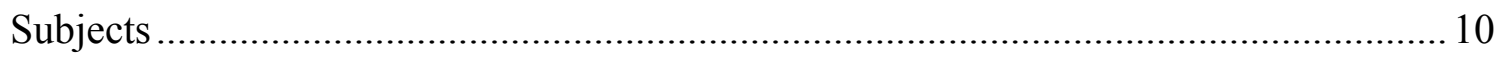

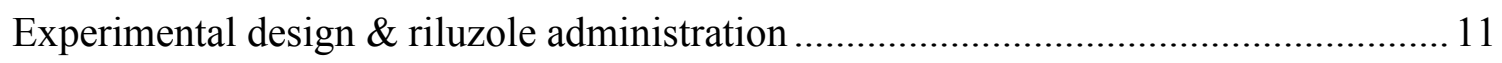

Water Radial Arm Maze ......................................................................................... 12

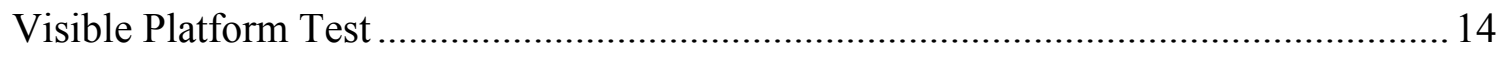

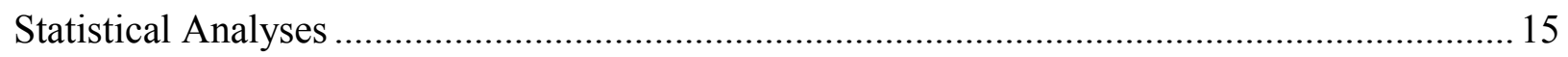

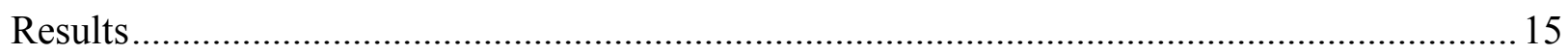

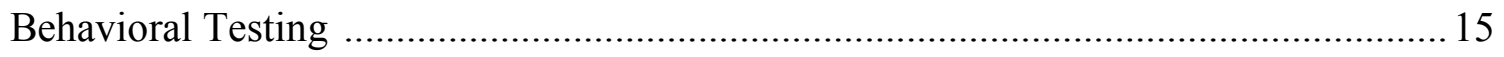

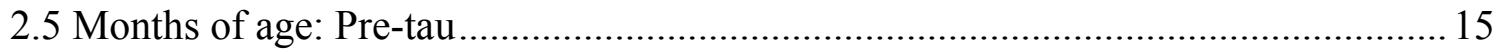

5 and 7.5 Months of age: Post-tau Acquisition .................................................. 16

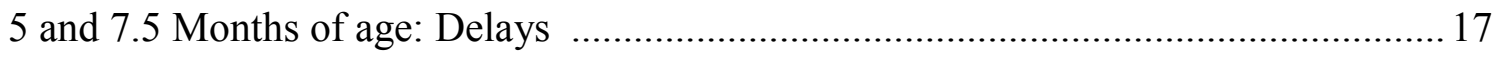

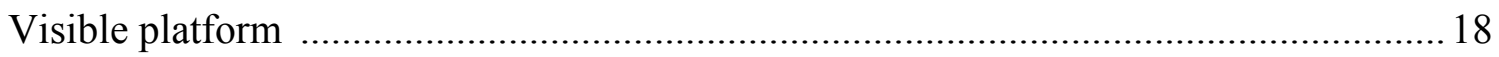

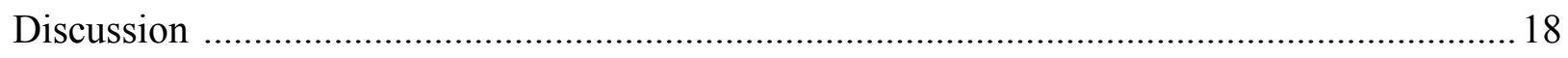

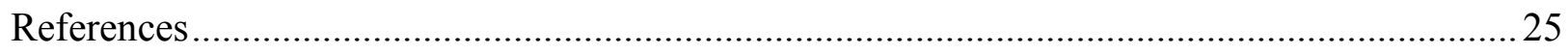




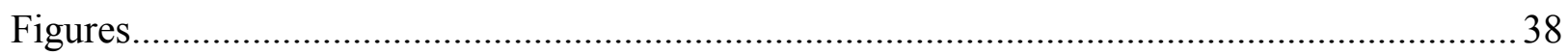

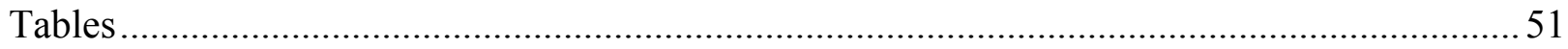


Attenuation of Spatial Memory Impairment in a

Tau Mouse Model of Alzheimer's Disease with Riluzole

Alzheimer's disease (AD) affects one in every nine adults age 65 and older and is the sixth leading cause of death in the United States (Alzheimer's Association, 2014.) Worldwide, the proportion of the population over 60 years of age is expected to double, with the total number expected to reach approximately 2 billion by the year 2050 (World Health Organization, 2014). Because aging is a strong predictor for developing AD (Plassman et al., 2007), the predicted rise in the aging population, in addition to an increased life expectancy, is expected to be associated with a dramatic increase in the incidence AD. If the current trend continues, healthcare, longterm care, and hospice care are projected to increase from a current mark of $\$ 214$ billion to $\$ 1.2$ trillion in 2050 (Alzheimer's Association, 2014). Meanwhile, pharmacologic treatments for AD have not been effective at slowing or halting the disease. It is imperative that alternative therapeutic targets be explored.

$\mathrm{AD}$ is characterized by extracellular plaques composed of beta-amyloid $(\mathrm{A} \beta)$, neurofibrillary tangles (NFTs) composed of hyperphosphorylated tau, and neuron loss. The discovery of mutations that increase the accumulation of $\mathrm{A} \beta$, resulting in familial early onset cases of AD (Tanzi et al., 1987), led to the development of the amyloid cascade hypothesis. This hypothesis states that deposition and aggregation of $A \beta$ is a critical step in the pathogenesis of AD, ultimately leading to tau pathology and neurodegeneration (Hardy \& Higgins, 1992). Most research to date has focused on identification and development of anti-amyloid therapies (Bard et al., 2000; Schenk et al., 1999; see Lannfelt et al., 2014 for review). Unfortunately, though treatments targeting $A \beta$ have been successful in reducing $A \beta$ levels and plaques in $A D$ patients, this reduction has not coincided with an increase in cognitive functioning and does not prevent 
progressive neurodegeneration (Holmes et al., 2008). In addition, the severity of dementia correlates with the number of NFTs in neocortical areas, rather than with the number of A $\beta$ plaques (Arriagada et al., 1992). Newer treatments including anti-A $\beta$ antibodies prevent downstream effects of toxic $A \beta$ such as loss of dendritic spines and reverse behavioral deficits in a mouse model of AD (Zago et al., 2012). Unfortunately, in clinical trials, A $\beta$ antibody treatment had no effect on individuals with mild-to-moderate AD (Doody et al., 2014). In addition, evidence suggests that tau pathology, once initiated, becomes self-sustaining and $A \beta$ independent (Katsuno et al., 2005). Targeting only A $\beta$, after the onset of tau pathology, is unlikely to alleviate cognitive deficits, as evidenced by the inability of $A \beta$ immunotherapy to reduce tau phosphorylation or tau-mediated pathology (Oddo et al., 2004).

Similarly, tau dysfunction can lead to neurodegeneration even in the absence of $\mathrm{A} \beta$ pathology (Hutton et al., 1998). Diseases in which tau hyperphosphorylation leads to cell dysfunction and cell death are collectively known as tauopathies, with AD being the most common of these diseases. In mouse models of tauopathies, all tau mice exhibiting tau pathology eventually develop cognitive deficits (Arrendash et al., 2004), and neuronal loss is a hallmark of tau mouse models (Spires et al., 2006). In contrast, though all mice expressing $A \beta$ mutations eventually develop amyloid plaques, some mice exhibit minimal or no cognitive deficits and little to no neuronal loss (Gruart et al., 2008). Interestingly, knocking out endogenous mouse tau in transgenic mice expressing human amyloid precursor protein (APP) protects against A $\beta$ mediated toxicity and reduces cognitive deficits, suggesting tau is necessary for A $\beta$-induced toxicity (Roberson et al., 2007). The cleavage of APP results in the production of A $\beta$ peptides (see Nhan et al., 2015 for review). If the reduction of tau attenuates cognitive decline even in the presence of $A \beta$, then identifying tau and the downstream effects mediated by tau could lead to 
new therapies that significantly improve the cognitive decline associated with AD. In addition, tau may mediate neuronal death through hyperactivity of brain regions.

Hyperactivity of areas of the memory network of the brain, such as the hippocampus, has been observed in patients at risk for the development of $\mathrm{AD}$, including individuals with mild cognitive impairment (MCI) (Dickerson et al., Hamalainen et al., 2007; Huijbers et al., 2015) and young healthy adult apolipoprotein E4 (APOE- $\varepsilon 4)$ allele carriers (Dennis et al., 2010). Presence of the APOE- $\varepsilon 4$ allele is a significant genetic risk factor associated with the development of lateonset AD (Corder et al., 1993; (see Huang, 2011 for review). Initially it was believed that the observed hyperactivity was a compensatory response where individuals with genetic risk for AD required additional effort from multiple brain regions to achieve similar memory performance compared to individuals not at genetic risk (Bondi et al., 2005). However, it is now believed that this hyperactivity is detrimental and contributes to memory impairment associated with AD pathology. For instance, individuals with $\mathrm{AD}$ have an increased risk for seizures compared with individuals without AD of the same age (Amatniek et al., 2006). Also, seizure and epileptiform activity is associated with earlier age of onset of cognitive impairments in individuals with MCI and $\mathrm{AD}$, with these symptoms often preceding diagnosis (Vossel et al., 2013).

Research using animal models provides further support for the impairing effects of hyperactivity, and the relationship between hyperactivity and AD. Mouse models of AD demonstrate hyperactivity prior to memory deficits (Bezzina et al., 2015). In addition, using a regulatable mouse model of AD, abnormal EEG activity occurred following APP expression and was delayed when APP expression was suppressed (Born et al., 2014). In addition, the observed hyperactivity is related to behavioral performance. Aged rats demonstrating hyperactivity in the hippocampus showed improved memory performance in spatial memory tasks following 
administration of treatment to decrease excess activity in the hippocampus (Koh et al., 2010).

Using a mouse model of AD, treatment to reduce the excess neuronal activity reduced impairments in learning and memory and reversed deficits in synaptic transmission in the hippocampus (Sanchez et al., 2012). Finally, in direct contrast to the hypothesis of compensatory action in the memory network, a reduction in hippocampal activity in individuals with MCI did not result in a worsening of memory performance as a consequence of reduced activity; rather, the reduced activity resulted in improved performance in behavioral testing (Bakker et al., 2012). These studies suggest that the observed hyperactivity may result in damage to the brain and may also be permissive for the development of AD.

Although the exact role is not known, it is believed that tau mediates hyperactivity. First, reducing the levels of endogenous tau protects against excitotoxin-induced seizures, where induced seizure severity and onset were reduced in mice with reduced levels of tau (Roberson et al., 2007). Because $A \beta$ levels were not altered, it is believed that tau was responsible for mediating this relationship. In addition, reduction of tau prevents spontaneous epileptiform activity and reduces the severity of seizures in a mouse model of AD (Roberson et al., 2011). In fact, there is a correlation between total tau protein levels found in the brain and the level of seizure activity in non-transgenic mice (DeVos et al., 2013). Similarly, knockdown of tau expression reduces seizure activity (Li et al., 2014). Overall, how exactly tau mediates hyperactivity is not known. It has recently been suggested that tau may alter glutamate receptor functioning (Warmus et al., 2014). Growing evidence, including our own data (Hunsberger et al., 2014), indicates that glutamate dysregulation is critical to the pathophysiology of AD. Addressing alterations in glutamatergic signaling may have therapeutic potential for those at risk for developing AD. 


\section{The glutamate life cycle}

Glutamate is the most common excitatory neurotransmitter in the central nervous system (CNS) (Daniels, Miller, \& DiAntonio, 2011) and is synthesized presynaptically from glucose or glutamine (Hamberger et al., 1979). Once synthesized, glutamate is packaged into synaptic vesicles by vesicular glutamate transporters (VGLUTs) (Daniels et al., 2011). VGLUTs control the amount of glutamate that is released into the synapse (Wojcik et al., 2004) when calcium enters the presynaptic terminal, causing the glutamate-containing vesicle to fuse with the terminal membranes (Sharma \& Vijayaraghavan, 2003).

After being released into the synapse, glutamate can bind to either ionotropic or metatropic glutamate receptors (mGluRs) (Hollmann, Hartley, \& Heinemann, 1991). Because $N$ methyl-D-aspartate receptors (NMDARs) are particularly important in the pathophysiology of AD (Reisberg et al., 2003), NMDARs will be described in greater detail. NMDARs are located synaptically (S-NMDAR) or extra-synaptically (E-NMDAR) (Hardingham, Fukunaga, \& Bading, 2002; Isaacson, 1999; Kullmann, Erdemli, \& Asztély, 1996). S-NMDARs are activated by glutamate in the synapse, whereas E-NMDAR activation requires glutamate spillover from the synapse, which typically occurs when extracellular glutamate levels are high (Hardingham et al., 2002). Termination of glutamate signaling occurs via reuptake by astrocytic, sodiumdependent glutamate transporters, including GLAST and GLT 1 (Pitt et al., 2003). After glutamate is cleared from the synapse, it is converted within astrocytes to glutamine (Sonnewald, Westergaard, \& Schousboe, 1997; Lieth et al., 2001). Glutamine is released into the extracellular space for uptake by presynaptic neurons, where it is converted back to glutamate, primarily by glutaminase, thus continuing the glutamate-glutamine cycle (Sibson et al., 1997). 
Below, a brief overview of glutamate's role as a neurotransmitter is described, followed by evidence demonstrating glutamate's role in the pathophysiology of AD.

\section{Why target glutamate?}

Glutamate, though essential for memory and learning (Jay, Zilkha, \& Obrenovitch, 1999), can cause cell death (Esclaire et al., 1997) by overstimulating E-NMDARs. This process, termed excitotoxicity, can occur via two mechanisms: increased glutamate release into the synapse or decreased glutamate clearance from the synapse. When glutamate levels are regulated, glutamate is released into the synapse and activates primarily only S-NMDARs; however, if extracellular glutamate accumulates, the extracellular glutamate spills over from the synaptic region and activates E-NMDARs. Activation of S-NMDARs has neuroprotective effects, by promoting brain derived neurotrophic factor (BDNF) expression, and increases learning and memory by activating cAMP response element-binding protein (CREB) (Hardingham et al., 2002). In addition, activation of S-NMDARs leads to the induction of long-term potentiation (LTP), which is critical for learning and memory (Lu et al., 2001). In contrast, activation of E-NMDARs deactivates CREB (Hardingham et al., 2002), activates long-term depression in regions of the hippocampus (Lu et al., 2001), and induces neuronal death (Hardingham et al., 2002). In addition, activation of E-NMDARs increases tau hyperphosphorylation by increasing the activity of kinases that phosphorylate tau (Allyson et al., 2010).

Using a tau mouse model of $\mathrm{AD}$, our lab recently found a significant increase in hippocampal VGLUT expression, leading to increased glutamate release, and a decrease in glutamate clearance (Hunsberger et al., 2014). Because these alterations in glutamate signaling may be responsible for memory deficits, which are observed in the tau mouse model of AD (Hoover et al., 2010; Hunsberger et al., 2014; Ramsden et al., 2005; SantaCruz et al., 2005), we 
hypothesized that administering treatment to regulate glutamate signaling would attenuate these memory deficits.

To test this hypothesis, we used riluzole, an FDA-approved medication for the neurodegenerative disease amyotrophic lateral sclerosis (ALS). Riluzole decreases glutamate release by reducing activation of voltage-dependent sodium channels, and increases glutamate clearance by increasing glutamate transporter expression (Liepert et al., 1997). We treated $\operatorname{rTg}(\operatorname{TauP301L}) 4510$ mice (herein referred to as TauP301L) with riluzole and examined memory performance. TauP301L mice exhibit memory deficits, tau pathology, and neuron loss (Ramsden et al., 2005). We predicted riluzole would attenuate the progression of memory decline typically observed in TauP301L mice following the expression of mutant tau (Ramsden et al., 2005). To determine whether riluzole attenuated memory deficits in TauP301L mice, we employed the eight-arm water radial arm maze task (WRAM), a task that examines spatial working memory (Engler-Chiurazzi et al., 2011).

\section{Water radial arm maze (WRAM)}

The WRAM is a hippocampal-based task that can be used to assess both reference memory errors and working memory errors in rodents (Gresack et al., 2003; Hyde et al., 1998, Lockrow et al., 2011). Reference memory errors are a measure of long-term memory, whereas working memory errors are a measure of short-term memory (Ciobica et al., 2012; Mladin et al., 2014; Stéphan; 2001) Reference memory errors reflect errors in learning of information that stays consistent throughout the entire experiment, such as the location of spatial cues around the room. This type of memory is required in order to learn the rules of the task (Shukitt-Hale et al., 2004). On the other hand, working memory errors reflect deficits in the ability of the rodents to hold changing information in memory (Frick et al., 1995). Working memory involves retaining 
information for short periods of time in regards to trial-specific details. For example, in the WRAM, after a platform is located, it is removed from the maze for all subsequent trials of that specific testing day. Because a trial-specific change occurred (i.e. the removal of a found platform), retaining the new information (i.e. there is no longer a platform in the just-chosen arm) would constitute working memory. Both reference and working memory errors can be examined using the WRAM procedure, a benefit of this task over those that primarily measure reference memory errors, such as the Morris water maze.

The ability to measure both types of errors is important in part because differential effects on working and reference memory can be observed. For instance, whereas estrogen treatment improves working memory performance, it does not affect performance on reference memory tasks in female rats (Fader et al., 1999). In addition, specific memory impairments appear to precede different disease states. For example, spatial reference memory errors are observed prior to motor impairments in experimental autoimmune encephalomyelitis, a mouse model of multiple sclerosis (Dutra et al., 2013). Further, reference and working memory are separately affected in different animal models of disease. Mice lacking specific subunits of NMDA receptors in the hippocampus exhibit impaired working memory, but normal reference memory (Bannerman et al., 2008; Niewoehner et al., 2007). This coincides with findings of impaired working memory functioning in mouse and rat models of AD (Cotel et al., 2012; Mustroph et al., 2012). However, knocking out the APOE gene, using APOE KO mice, improves reference memory compared to controls, without affecting working memory (Avdesh et al., 2011). Because both spatial reference and working memory are negatively affected in rodent models as well as in individuals with AD (Crawford et al., 2013; Stopford et al., 2012), assessing both of these types of memory errors in our mouse model of AD has clinical implications. 


\section{Statement of the problem}

Alzheimer's disease is a progressive neurodegenerative disorder that currently has no cure and is the most common form of dementia (Alzheimer's Association, 2013). AD is characterized by intracellular neurofibrillary tangles (NFTs) containing hyperphosphorylated tau and extracellular plaques comprised of beta-amyloid (A $\beta)$. Pharmacologic interventions have been effective in reducing $A \beta$ levels; however, these reductions have not led to an increase in memory functioning (Holmes et al., 2008). Because of the shortcomings of research focusing on $\mathrm{A} \beta$, it is necessary to investigate other possible causes and therapeutic targets, such as tau and downstream alterations produced following tau pathology.

While the exact mechanism by which hyperphosphorylated tau causes cell death is not known, prior research (Amadoro et al., 2005; Esclaire et al., 1997; Hoover et al., 2010; Tackenberg et al., 2013) shows a relationship between hyperphosphorylated tau and increased activation of ENMDARs by glutamate. Because glutamate increases tau phosphorylation (Jämsä et al, 2006), reductions in extracellular glutamate may halt the accumulation of hyperphosphorylated tau deposits.

Riluzole, an FDA-approved treatment for amyotrophic lateral sclerosis, reduces the spontaneous release of glutamate (Chéramy et al., 1992) and increases glutamate uptake (Liepert et al., 1997), leading to decreases in extracellular glutamate (Fumagalli et al., 2007). The ability of riluzole to increase glutamate uptake is mediated by glutamate transporters located on astrocytes, such as GLT-1 (Banasr et al., 2010; Fumagalli et al., 2008). Additionally, the pharmacokinetic profile of riluzole is ideal: $90 \%$ is absorbed following oral administration, the half-life is 12 hours, and primarily only mild side effects have been observed (Food and Drug Administration, 2008). The most common side effects are nausea and asthenia, which includes 
muscle weakness and fatigue (Miller et al., 2012; Lemmon et al., 2015). To determine whether decreasing extracellular glutamate attenuates AD-related memory deficits, we administered riluzole to TauP301L mice and measured spatial memory performance with the WRAM.

\section{Method}

\section{Subjects}

In total, 68 male and female mice were used (Figure 1A). Original transgenic mice were donated by Dr. Karen Ashe (University of Minnesota). Transgenic mice were generated using a system of responder and activator transgenes, which has been described previously (Ramsden et al., 2005; SantaCruz et al., 2005). The activator transgene in a mouse line of a 129S6 background strain consists of the tet-off tetracycline transactivator (tTA) open reading frame placed downstream of calcium/calmodulin kinase II (CaMKII) promoter elements. Responder mice in an FVB background strain were generated by placing a tetracycline- responsive element (TRE) upstream of cDNA encoding human four-repeat tau lacking the N-terminal sequence (4R0N) with the P301L mutation. Heterozygous responder and activator mice were bred together to produce TauP301L mice (TauP301L/tTA: +,+) and three controls $(+,-),(-,+)$, and $(-,-)$. Only the $(-,+)$ control was used because littermate controls do not express tau or exhibit behavioral impairments (Ramsden et al., 2005; SantaCruz et al., 2005), but the use of $(-,+)$ mice allow us the ability to control for the expression of tTA (Hunsberger et al., 2014).

Through the use of CaMKII promoter, expression of tau is restricted to the hippocampus and neocortex, regions altered in AD (Pearson et al., 1985) (Figure 1B). The use of the tet-off system allows for the regulatable expression of tau. In the tet-off system, the tTA protein binds to TRE, which allows transcription and protein expression to occur (Liu et al., 2008). If doxycycline, a tetracycline derivative, is introduced to the drinking water or food, the tTA 
protein cannot bind to TRE leading to the suppression of tau expression. Because the expression of P301L tau during development can produce alterations not observed if P301L tau is first expressed in adulthood (Caouette et al., 2013), P301L tau expression was suppressed using doxycycline during brain development to ensure deficits and morphological changes in the brain not related to $\mathrm{AD}$ did not occur. Mice received 40 parts per million (ppm) doxycycline hyclate via water bottles from birth until 2.5 months of age. Doxycycline was purchased from SigmaAldrich (St. Louis, MO, USA). Breeder dams were placed on doxycycline two weeks prior to breeding to ensure maternal levels stabilized before pregnancy. Mice were group housed $3-5$ per cage in a temperature and humidity-controlled colony room with a 12:12 light/dark cycle. Food was provided ad libitum. All experimental procedures were approved by the West Virginia University Animal Care and Use Committee.

\section{Experimental design \& riluzole administration}

To ensure differences between TauP301L mice and control littermates were not present prior to the onset of tau expression, behavioral testing was conducted with the water radial arm maze (WRAM) at 2.5 months of age while the mice were still on doxycycline. Once it was confirmed that deficits were not present prior to the expression of tau, TauP301L mice were removed from doxycycline and pseudo-randomly assigned to vehicle or riluzole treatment groups based on pre-tau WRAM performance, resulting in 3 groups: Veh-Controls $(\mathrm{N}=23$; $\mathrm{n}=$ 11 females, $\mathrm{n}=12$ males $)$, Veh-TauP301L $(\mathrm{N}=24 ; \mathrm{n}=9$ females, $\mathrm{n}=15$ males $)$, and RilTauP301L $(\mathrm{N}=21 ; \mathrm{n}=13$ females, $\mathrm{n}=8$ males $)$. Ril-TauP301L mice received riluzole, whereas Veh-Controls and Veh-TauP301L mice received vehicle alone.

Riluzole was purchased from Selleck Chemicals (Houston, TX, USA). Riluzole and 1\% w/v saccharin (vehicle) was mixed together in deionized water for approximately 2 hours under 
low heat until completely dissolved. The dissolved riluzole was then administered to mice via water bottles changed every three days. Water bottles were weighed daily, and the concentration of riluzole was adjusted every 72 hours such that intake remained at approximately 12.5 $\mathrm{mg} / \mathrm{kg} /$ day per mouse for each cage. This dose was chosen because it has been shown to increase GLT-1 expression, restore brain-derived neurotrophic factor expression, and does not affect locomotor activity when administered to mice via drinking water (Gourley et al., 2012). In human patients, two of the most frequent side effects of riluzole include nausea and asthenia, or general weakness (Miller et al., 2012). Throughout testing, body weights of the mice were recorded and swim speed was measured during behavioral testing. No differences in bodyweight were observed among the treatment groups at $2.5,5$, or 7.5 months of age $(p \mathrm{~s}>.10)$. In addition, swim speeds did not differ in the Morris water maze $(p s>.10)$. These results suggest that the dose of riluzole administered in the study was not toxic and did not produce nausea or asthenia.

Mice underwent further memory testing at 5 and 7.5 months of age, after 2.5 and 5 months of tau expression, respectively. At both time points, mice underwent WRAM testing, followed by additional cognitive testing. At the final time point, the last test completed was the visible platform task. Although other tests were used, the current project will focus solely on the results obtained from WRAM and visible platform testing. During testing at 7.5 months of age, a male mouse from the Veh-Controls group died, reducing the sample size for testing at 7.5 months of age.

Water Radial Arm Maze. The WRAM was performed as previously described (Bimonte-Nelson et al., 2003). The maze was constructed of white plastic with 8 arms $(10.4 \mathrm{~cm}$ wide $x 38.1 \mathrm{~cm}$ long x $38.9 \mathrm{~cm}$ in high) spaced $5 \mathrm{~cm}$ apart. The middle circle, from which the eight arms extend, has a diameter of $38.9 \mathrm{~cm}$. The maze was filled with room temperature water 
(approximately $21^{\circ} \mathrm{C}$ ) and made opaque with white non-toxic paint. The distance from the water level to the top of the maze was approximately $5 \mathrm{~cm}$. Four of the arms contained platforms located $1 \mathrm{~cm}$ below the surface of the water. The location of the platforms were counterbalanced across the groups, but remained fixed for a particular mouse for the duration of testing at a particular age. A platform was never in more than two adjacent arms or in the "start arm" from which a mouse was released. Salient extra-maze cues remained constant for the duration of testing at a particular age. However, both the location of the platform arms and the cues changed for testing at subsequent ages.

Once released from the start arm, the mouse had 2 minutes to locate a hidden platform. If the allotted time expired, the mouse was guided to the nearest platform. Once a platform was found, the mouse remained on the platform for 15 seconds. At that point, the mouse was removed and placed in the holding cage lined with paper towels and warmed to $\sim 31{ }^{\circ} \mathrm{C}$ by a heating pad and heat lamp for 30 seconds to prevent hypothermia. During the interval, the justchosen platform was removed. After 30 seconds elapsed, the mouse was placed in the start arm again and allowed to locate a different platform. Each mouse was given 4 trials per session and one session per day. One platform was removed after each trial until only one platform remained in trial 4. Thus, each subsequent trial resulted in an increase in memory load, as the mice had to remember not only the locations of the remaining platforms, but also the location of the platforms that had already been found and removed (Bimonte-Nelson, et al., 2003).

Each mouse was given 1 session per day for 11 consecutive days. Day 1 was considered a training session because the mice did not have previous experience in the maze, whereas days 211 were considered the testing sessions for acquisition (Engler-Chiurazzi et al., 2011). On day 12, a four-hour delay was inserted between trials 2 and 3. At 5 and 7.5 months of age, a 13th day 
of testing was added, and a six-hour delay was inserted between trials 2 trial 3. Delays were inserted to increase memory demand for the trials following the delay, i.e., trials 3 and 4 (EnglerChiurazzi et al., 2011).

An arm entry was defined as all four paws entering into an arm of the maze. Working memory correct errors were defined as the number of first and repeat entries into any arm where a platform had been during a previous trial. Reference memory errors were defined as the number of first entries into any arm that never contained a platform. Working memory incorrect errors were defined as the number of repeat entries into an arm that never contained a platform, i.e., repeat entries into a reference memory arm (Figure 2). Errors were analyzed for each daily session of acquisition (days 2-11). For days 12 and 13, trials 1-4 were analyzed (Braden et al., 2010).

Visible Platform Test. To ensure any deficits observed in the WRAM were not due to visual or motor deficits, the visible platform test was performed as previously described (Bimonte-Nelson et al., 2003) at the end of the experiment at 7.5 months of age. The tub $(61 \mathrm{~cm}$ length $\times 61 \mathrm{~cm}$ width $\times 21 \mathrm{~cm}$ height) was partially filled with room temperature water (approximately $21^{\circ} \mathrm{C}$ ) made opaque with white non-toxic paint. The distance of the water from the top of the tub was approximately $6.4 \mathrm{~cm}$. A black platform, with a flag raised $13 \mathrm{~cm}$ in height containing an "S" shaped character mounted on top, was placed approximately $2.5 \mathrm{~cm}$ above the water level. Extra-maze cues were removed from the testing area, and white curtains were hung around the testing room. Briefly, a mouse was placed into the tub so that it entered facing the wall opposite the platform. The mouse was given 2 minutes to swim to the platform. If the mouse found the platform within the allotted time limit, the mouse remained on the platform for 20 seconds; if the mouse did not find the platform within the allotted time limit, the mouse was 
gently guided to the platform. After each mouse completed the first trial, the platform was moved to a previously determined location near the back wall of the tub. All mice were given 5 independent trials, with approximately 10 minutes in between each trial.

\section{Statistical Analyses}

All statistical analyses were performed using JMP (SAS, Cary, NC, USA). ANOVAs were used to examine differences in memory performance for each error at each age. For all analyses, main effects of Group (Veh-Controls, Veh-TauP301L, and Ril-TauP301L), Sex (Male vs Female), and the Group*Sex interactions were assessed. Due to the longitudinal nature of this study, repeated measures ANOVAs (RMANOVA) were also used to assess changes in cognitive performance with longer durations of tau expression. Day or Trial served as the within-subject variables for RMANOVA analyses. All significant omnibus tests were followed by Dunnett's post-hoc analyses with Veh-TauP301L used as the comparison group. The critical alpha level was set to 0.05 , and values in the figures represent means \pm SEM.

\section{Results}

\section{Behavioral Testing}

2.5 Months of age: Pre-tau. During acquisition trials at 2.5 months of age, significant effects of Day for time $[F(9,522)=3.39, p=.0005]$, WMC $[F(9,522)=3.33, p=.0006]$, WMI $[F(9,522)=$ 5.22, $p<.0001]$, and REF $[F(9,522)=8.74, p<.0001]$ were observed. For time, WMI, and REF, mice improved with additional training, whereas for WMC, mice made more errors with additional training (Figure 3), suggesting that mice may require additional training in order to reduce WMC errors as opposed to REF or WMI errors. Though male mice, regardless of Group status, took longer to find the platform initially, males and females performed similarly with additional training [Day*Sex: $F(9,522)=2.00, p=.04$ ] (Figure 4). There were no differences, 
however, among the Groups (Veh-Controls, Veh-TauP301L, and Ril-TauP301L) for any measure $(p s>.10)$ (Table 2), suggesting similar acquisition prior to the onset of tau expression.

On Day 12, a 4-hour delay was inserted between trials 2 and 3 to increase the memory load (Braden et al., 2010), and the number of errors was compared. Male mice, regardless of Group status, made significantly more WMI errors than female mice $[$ Sex: $F(1,58)=3.96, p$ $=.05]$ (Figure 5). No other differences were observed prior to the expression of tau $(p \mathrm{~s}>.10)$ (Table 3), indicating similar overall pre-tau memory performance among the Groups.

5 and 7.5 Months of age: Post-tau Acquisition. Unless otherwise noted, there were significant Day effects for time, WMC, WMI and REF errors at 5 and 7.5 months of age $(p s<.05)$ and will not be discussed in detail (Figure 6, 8).

Because no differences were found at 2.5 months of age, prior to tau expression, mice were tested at 5 months of age, 2.5 months post tau expression. During acquisition trials at 5 months of age, there was no effect of Day for WMC, showing that no improvement was observed in WMC with increased training $[F(9,522)=1.05, p<.40]$ (Table 4). A significant interaction in REF errors was observed [Day*Group: $F(18,522)=1.77, p<.05$ ], where VehControls $[F(9,198)=3.98, p<.0001]$ and Ril-TauP301L $[F(9,180=4.76, p<.0001]$ improved in REF performance with additional training, whereas Veh-TauP301L mice did not $[F(9,207]=$ $1.59, p=.12]$ (Figure 6D). In addition, male mice took longer to complete the trials than female mice [Sex: $F(1,58)=6.03, p=.02]$, and male mice made more $\mathrm{WMC}[\operatorname{Sex}: F(1,58)=4.21, p=$ 0.04], WMI [Sex: $F(1,58)=5.10, p=.03]$, and REF errors than female mice $[$ Sex: $F(1,58)=$ 5.90, $p=.02]$ (Figure 7). 
Finally, at 7.5 months of age, after 5 months of tau expression, there were no significant effects of Group or Sex, and there were no Sex*Group interactions for any measure $(p \mathrm{~s}>.10)$ (Table 5).

5 and 7.5 Months of age: Delays. Following analysis of acquisition, or testing days in which mice learned the task, we analyzed testing days in which a day was inserted. A RMANOVA at 5 months of age of trials 1, 2, 3, and 4 of Day 12 was conducted to determine the effects of an increasing memory load when a 4-hour delay was inserted between trials 3 and 4 (EnglerChiurazzi et al., 2011). There were no Group, Sex, or Group*Sex interactions ( $p$ s > .10) (Table 6), suggesting a 4-hour delay was not sufficient to reveal memory deficits after 2.5 months of tau expression.

To determine if a longer delay would unmask memory deficits, a 6-hour delay was inserted between trials 3 and 4 on Day 13 to further increase difficulty (Engler-Chiurazzi et al., 2011). A RMANOVA of trials 1, 2, 3, and 4 of Day 13 revealed Veh-TauP301L mice made significantly more WMI errors [Group: $F(2,58)=5.49, p=0.007$ ], an effect attenuated by riluzole (Figure 9). Veh-TauP301L mice repeatedly returned into arms which never contained a platform, demonstrating deficits in a measure of short-term memory. No other differences for any error were observed (Table 7).

We next analyzed delay trials at 7.5 months of age because this allowed for the longest amount of tau expression. When a 4-hour delay was inserted on Day 12 at 7.5 months of age, after 5 months of tau expression, a RMANOVA of trials 1-4 of Day 12 revealed that VehTauP301L mice made significantly more REF errors as compared to Veh-Controls [Group: $F(2,57)=4.72, p=.01]$ (Figure 10). No other differences for any error were observed (Table 8). 
Analysis of trials 1-4 of Day 13 at 7.5 months of age demonstrated that Veh-TauP301L mice made more WMI errors with increasing memory load [Trial*Group: $F(6,171)=2.68, p$ $=.02]$ (Figure 11). This shows that on the trial with the highest memory load, Veh-TauP301L mice repeatedly entered arms which never contained a platform, demonstrating deficits in shortterm memory. This effect was reduced by administration of riluzole. No effects of Group, Sex, or Group*Sex interactions were observed for any other error (Table 9).

Finally, memory performance at 5 and 7.5 months of age was compared among the groups (Table 10). At each age, data from Trials 3 and 4 were averaged together and then analyzed because these trials follow the 6-hour delay and have the highest memory demand (Engler-Chiurazzi et al., 2011). A RMANOVA of trials 3 and 4 following the 6-hour delay on Day 13 at 5 and 7.5 months of age revealed Veh-TauP301L mice took more time to complete trials 3 and 4 [Group: $F(2,57)=4.02, p=.02$ ] (Figure 12) and made more WMI errors [Group: $F(2,57)=7.96, p=.0009]$ (Figure 13), regardless of age. WMI errors committed at both ages were rescued by the administration of riluzole.

\section{Visible platform}

To determine whether any mice were demonstrating visual or motor deficits, visible platform training was conducted at the conclusion of behavioral testing. There were no differences in time to find the visible platform [Group: $F(2,57)=2.10, p=.13$; Sex: $F(1,57)=$ $0.80, p=.37$; Group*Sex: $F(2,57)=2.63, p=.08$ ] (Table 11). Results suggest there were no differences in visual or motor deficits in the mice in the current study.

\section{Discussion}

We examined the effectiveness of riluzole in attenuating memory deficits using a TauP301L mouse model of AD. Altered glutamate signaling has been observed in TauP301L mice 
and correlates with memory performance in hippocampal-dependent tasks (Hunsberger et al., 2014). To determine if attenuating glutamate dysregulation could rescue the observed cognitive impairments, we administered riluzole, which regulates glutamate signaling (Liepert et al., 1997), and examined the effects on memory using the hippocampal-dependent water radial arm maze (WRAM). Our findings suggest that TauP301L mice exhibited memory deficits, an effect attenuated by riluzole.

The WRAM is a spatial water maze memory task that requires animals to use spatial cues around the room to learn the position of hidden platforms. The use of the WRAM eliminates potential confounds due to motivation to locate food and also avoids the potential issue of thigmotaxic behavior, which occurs when mice swim close to the walls in circular tubs and do not learn a search strategy (Bimonte-Nelson et al., 2003). The WRAM also has the benefit of increasing memory load due to the removal of a platform following each trial (Bimonte-Nelson et al., 2003) and the insertion of delays following acquisition testing (Braden et al., 2010).

Results from the WRAM indicated that, as anticipated, there were no differences between TauP301L and Control mice prior to the onset of tau expression. However, there were differences between males and females on the delay trial. Similarly, males perform better than females in WRAM testing (Gresack \& Frick, 2003). However, in the current study, male mice made more errors than female mice. The reported difference in this study may be due to the use of different background strains. In addition, different testing procedures were used. In the current study, acquisition consisted of 11 days, followed by testing days in which a delay was inserted; during pre-tau testing, male and female mice displayed similar performance during acquisition; however, male mice made more errors on the delay trial, which was not conducted in the study by Gresack and Frick (2003). 
At 5 months of age, 2.5 months post-tau expression, results from the WRAM indicated that Veh-TauP301L mice made significantly more errors than Ril-TauP301L mice. However, there was no significant difference in errors made between Veh-TauP301L mice and Veh-Controls. It is possible that this time point may represent an early stage in the progression from normal memory functioning to impaired memory functioning. At 7.5 months of age, 5 months post-tau expression, Veh-TauP301L mice made significantly more errors than Ril-TauP301L mice and Veh-Controls. Riluzole not only attenuated memory deficits but resulted in TauP301L memory performance that was similar to the performance of controls. The findings of this study suggest that TauP301L mice that received riluzole displayed similar memory performance as non-transgenic mice. This suggests that regulating glutamate levels attenuates memory deficits in TauP301L mice.

WRAM testing allows for measurements of time to find the platform, working memory correct errors (WMC), working memory incorrect errors (WMI), and reference errors (REF). Although time to find the hidden platform can be used for analysis, potential confounds when analyzing time to find the platform include swim speed and irregular swim behavior such as floating. Because tracking software was not used for WRAM testing, swim speed could not be analyzed. WMC errors did not differ among the groups. One potential reason for this could be the age at which testing was conducted. We conducted memory testing at $2.5,5$, and 7.5 months of age, while suppressing tau expression for the first 2.5 months. Because severe memory impairments are not yet expected after 2.5 and 5 months of tau expression, it is possible that WMC errors are not sensitive enough to detect such subtle memory impairments. Rather WMC errors may be a more sensitive measure for older mice, after a longer period of tau expression. WMI errors were the most sensitive error in the current study. WMI errors, which are the number of times a mouse re-enters an arm that never contained a platform, have qualities similar to 
preservative behavior. Preservative behavior is defined as a continuation of behavior without an appropriate stimulus (Son et al., 2013) and is often seen in patients with AD and other dementias (Lamar et al., 1997; Possin et al., 2012). In the current study, we observed an increase in WMI errors as trials progressed and became more difficult.

Throughout each day of WRAM testing, memory load increases (Bimonte-Nelson et al., 2003), meaning that, on each successive trial, mice have to remember more information. Following the first trial, in order to complete the task, the mice must remember where the four platforms are located and which platforms have already been located. The addition of a delay further increases the memory load of trials three and four. Increasing memory load is relevant to Alzheimer's disease patients because the hippocampus, which is damaged in AD (Kril et al., 2002; Salat et al., 2010), is necessary for normal performance in memory tasks with high memory load (Sannino et al., 2012). In addition, increasing the memory load by increasing the delay time may also have relevance to disorders with hippocampal dysfunction. Finally, because the current study examined memory deficits at an early time point in the progression of disease pathology, increasing the memory load by increasing the time of the delays may be necessary to ensure the task is sensitive enough to identify differences in memory performance among groups.

Individuals with $\mathrm{AD}$ display working memory impairments, which become more pronounced as increased information is presented, characteristic of a high memory load (Stopford et al., 2012). Also, individuals with AD display impairments in memorizing and retracing a sequence of body turns when tested in a navigation task developed for mice and adapted to humans (Bellassen et al., 2012; Bianchini et al., 2014). Specifically, short-term memory in relation to navigating in an unfamiliar environment is impaired in the early stages of $\mathrm{AD}$, where patients with $\mathrm{AD}$ are unable to identify similar landscape images when topographical features are changed. (Bird 
et al., 2010). WRAM testing also measures reference memory errors. Reference memory involves being presented with information that stays constant over time, whereas working memory involves using information that changes with a short duration of time (Gamoh et al., 1999; Jarred et al., 1984). Spatial reference memory and spatial working memory appear to have different underlying processes. For instance, mice lacking a specific glutamate receptor subunit (GluR1) display working memory deficits but not reference memory impairments (Reisel et al., 2002; Schmitt et al., 2003). Further research on how these two types of memory work together, yet also function separately, is warranted.

Spatial memory was rescued in the present study by the administration of riluzole. While it is believed this rescue occurred through regulating glutamate levels, the exact mechanisms by which riluzole alters glutamate regulation is not fully understood. Riluzole increases the rate of glutamate uptake (Azbil, 2000), which is mediated by astrocytic glutamate transporters such as GLT-1 (Banasr et al., 2010, Fumagalli et al., 2008). Riluzole also decreases the amount of glutamate that is released. However, it is unclear if riluzole inhibits release by inhibiting voltagedependent calcium channels (Wang et al., 2004), sodium channels (Urbani \& Belluzzi., 2000; Zona et al., 1998), or potassium channels (Xu et al., 2001; Zona et al., 1998).

Riluzole shows translational potential because it increases astrocytic glutamate uptake even at low concentrations (Santos Frizzo et al., 2004). Riluzole has shown anxiolytic-like effects (Sugiyama et al., 2012), anti-depressant like effects (Gourley et al., 2012), and has shown numerous neuroprotective effects including reducing neuron death and degeneration (Cabaj \& Slawinska et al., 2012; Carbone et al., 2012; Mazzone \& Nistri., 2011; Verhave et al., 2012).. Although the present study did not examine the direct ability of riluzole to regulate glutamate levels, our lab examined the ability of riluzole to regulate glutamate using microelectrode arrays 
following the completion of behavioral testing. TauP301L mice demonstrated increased glutamate release and decreased glutamate uptake, both of which were returned to control levels following riluzole treatment.

A limitation of the present study is the absence of a control littermate group that received administration of riluzole. Therefore, the effect of riluzole on mice without the P301L mutation cannot be concluded from this study. The present study extends findings of the ability of riluzole to improve memory performance in animal models of brain dysfunction, such as ischemia (Malgouris et al., 1989). However, the present study did not determine whether riluzole administration has the potential to improve memory performance in non-transgenic mice.

Although our lab has demonstrated the alteration of glutamate signaling in a commonly used mouse model of $\mathrm{AD}$, glutamate may not be the only cause of hyperexcitability leading to neurodegeneration. For example, $\gamma$-aminobutyric acid (GABA) is the major inhibitory neurotransmitter in the CNS (see Li \& Xu, 2008 for review). Reductions in GABA signaling can also result in hippocampal hyperexcitability (Lang et al., 2014; Nieto-Gonzalez et al., 2011; Olmos-Serrano et al., 2010), presumably by reducing tonic inhibition of glutamatergic neurons. It is plausible then that hyperactivity could be due to the interaction between reduced GABA activity and increased glutamate activity. In addition, tau pathology has detrimental effects on GABAergic neuron functioning, leading to altered synaptic plasticity and memory deficits (Levenga et al., 2013). Determining the roles of the GABAergic and glutamatergic systems and how they interact with tau to mediate hyperexcitability in neurodegenerative disorders should be further investigated.

In conclusion, we administered riluzole to TauP301L mice to determine if regulating glutamate levels could rescue memory deficits. Our results demonstrate that TauP301L mice 
exhibit memory impairments, and these deficits are attenuated with riluzole administration. Based on our lab's findings of increased glutamate release and decreased glutamate clearance in TauP301L mice (Hunsberger et al., 2014), combined with riluzole's ability to improve glutamate signaling, glutamate regulation may be responsible for the attenuation of memory deficits that were observed in this study. In addition, decreased glutamate clearance is observed in patients with AD (Ferrarese et al., 2000; Masliah et al., 1996. Therefore, altering glutamate dysregulation has clinical implications for AD patients. The findings from this study provide a first step towards the development of an open-label investigation of riluzole for those at risk for AD. 


\section{References}

2014 alzheimer's disease facts and figures. (2014). Alzheimers Dement, 10(2), e47-92. doi:S1552526014000624

Allyson, J., Dontigny, E., Auberson, Y., Cyr, M., \& Massicotte, G. (2010). Blockade of NR2Acontaining NMDA receptors induces tau phosphorylation in rat hippocampal slices. Neural Plast, 2010, 340168. doi:10.1155/2010/340168

Amadoro, G., Ciotti, M. T., Costanzi, M., Cestari, V., Calissano, P., \& Canu, N. (2006). NMDA receptor mediates tau-induced neurotoxicity by calpain and ERK/MAPK activation. Proc Natl Acad Sci U S A, 103(8), 2892-7. doi:0511065103 [pii] 10.1073/pnas.0511065103

Amatniek, J. C., Hauser, W. A., DelCastillo-Castaneda, C., Jacobs, D. M., Marder, K., Bell, K., . . Stern, Y. (2006). Incidence and predictors of seizures in patients with alzheimer's disease. Epilepsia, 47(5), 867-72. doi:EPI554 [pii] 10.1111/j.1528-1167.2006.00554.x

Arendash, G. W., Lewis, J., Leighty, R. E., McGowan, E., Cracchiolo, J. R., Hutton, M., \& Garcia, M. F. (2004). Multi-metric behavioral comparison of APPsw and P301L models for alzheimer's disease: Linkage of poorer cognitive performance to tau pathology in forebrain. Brain Res, 1012(1-2), 29-41. doi:10.1016/j.brainres.2004.02.081 [doi] S0006899304004688

Arriagada, P. V., Growdon, J. H., Hedley-Whyte, E. T., \& Hyman, B. T. (1992). Neurofibrillary tangles but not senile plaques parallel duration and severity of alzheimer's disease. Neurology, 42(3 Pt 1), 631-9.

Avdesh, A., Wong, P., Martins, R. N., \& Martin-Iverson, M. T. (2011). Memory function in a mouse genetic model of alzheimer's disease. J Alzheimers Dis, 25(3), 433-44. doi:0272810220102476 [pii] 10.3233/JAD-2011-101944

Azbill, R. D., Mu, X., \& Springer, J. E. (2000). Riluzole increases high-affinity glutamate uptake in rat spinal cord synaptosomes. Brain Res, 871(2), 175-80. doi:S0006-8993(00)02430-6

Bakker, A., Krauss, G. L., Albert, M. S., Speck, C. L., Jones, L. R., Stark, C. E., . . Gallagher, M. (2012). Reduction of hippocampal hyperactivity improves cognition in amnestic mild cognitive impairment. Neuron, 74(3), 467-74. doi:S0896-6273(12)00325-X [pii] 10.1016/j.neuron.2012.03.023

Banasr, M., Chowdhury, G. M., Terwilliger, R., Newton, S. S., Duman, R. S., Behar, K. L., \& Sanacora, G. (2010). Glial pathology in an animal model of depression: Reversal of stressinduced cellular, metabolic and behavioral deficits by the glutamate-modulating drug riluzole. Mol Psychiatry, 15(5), 501-11. doi:mp2008106 [pii] 10.1038/mp.2008.106 
Bannerman, D. M., Niewoehner, B., Lyon, L., Romberg, C., Schmitt, W. B., Taylor, A., . . Rawlins, J. N. (2008). NMDA receptor subunit NR2A is required for rapidly acquired spatial working memory but not incremental spatial reference memory. J Neurosci, 28(14), 3623-30. doi:28/14/3623 [pii] 10.1523/JNEUROSCI.3639-07.2008

Bard, F., Cannon, C., Barbour, R., Burke, R. L., Games, D., Grajeda, H., . . Yednock, T. (2000). Peripherally administered antibodies against amyloid beta-peptide enter the central nervous system and reduce pathology in a mouse model of alzheimer disease. Nat Med, 6(8), 916-9. doi: $10.1038 / 78682$

Bellassen, V., Igloi, K., de Souza, L. C., Dubois, B., \& Rondi-Reig, L. (2012). Temporal order memory assessed during spatiotemporal navigation as a behavioral cognitive marker for differential alzheimer's disease diagnosis. J Neurosci, 32(6), 1942-52. doi:32/6/1942 [pii] 10.1523/JNEUROSCI.4556-11.2012

Bezzina, C., Verret, L., Juan, C., Remaud, J., Halley, H., Rampon, C., \& Dahan, L. (2015). Early onset of hypersynchronous network activity and expression of a marker of chronic seizures in the tg2576 mouse model of alzheimer's disease. PLoS One, 10(3), e0119910. doi:10.1371/journal.pone.0119910 [doi] PONE-D-14-37296

Bianchini, F., Di Vita, A., Palermo, L., Piccardi, L., Blundo, C., \& Guariglia, C. (2014). A selective egocentric topographical working memory deficit in the early stages of alzheimer's disease: A preliminary study. Am J Alzheimers Dis Other Demen, 29(8), 749-54. doi:1533317514536597 [pii] 10.1177/1533317514536597

Bimonte-Nelson, H. A., Hunter, C. L., Nelson, M. E., \& Granholm, A. C. (2003). Frontal cortex BDNF levels correlate with working memory in an animal model of down syndrome. Behav Brain Res, 139(1-2), 47-57. doi:S0166432802000827

Bird, C. M., Chan, D., Hartley, T., Pijnenburg, Y. A., Rossor, M. N., \& Burgess, N. (2010). Topographical short-term memory differentiates alzheimer's disease from frontotemporal lobar degeneration. Hippocampus, 20(10), 1154-69. doi:10.1002/hipo.20715

Boekhoorn, K., Terwel, D., Biemans, B., Borghgraef, P., Wiegert, O., Ramakers, G. J., . . . Lucassen, P. J. (2006). Improved long-term potentiation and memory in young tau-P301L transgenic mice before onset of hyperphosphorylation and tauopathy. J Neurosci, 26(13), 3514-23. doi:26/13/3514 [pii] 10.1523/JNEUROSCI.5425-05.2006

Bondi, M. W., Houston, W. S., Eyler, L. T., \& Brown, G. G. (2005). fMRI evidence of compensatory mechanisms in older adults at genetic risk for alzheimer disease. Neurology, 64(3), 501-8. doi:64/3/501 [pii] 10.1212/01.WNL.0000150885.00929.7E 
Born, H. A., Kim, J. Y., Savjani, R. R., Das, P., Dabaghian, Y. A., Guo, Q., . . Jankowsky, J. L. (2014). Genetic suppression of transgenic APP rescues hypersynchronous network activity in a mouse model of alzeimer's disease. J Neurosci, 34(11), 3826-40. doi:34/11/3826 [pii] 10.1523/JNEUROSCI.5171-13.2014

Braden, B. B., Talboom, J. S., Crain, I. D., Simard, A. R., Lukas, R. J., Prokai, L., . . BimonteNelson, H. A. (2010). Medroxyprogesterone acetate impairs memory and alters the GABAergic system in aged surgically menopausal rats. Neurobiol Learn Mem, 93(3), 44453. doi:S1074-7427(10)00003-1 [pii] 10.1016/j.nlm.2010.01.002

Brown, R. E., \& Wong, A. A. (2007). The influence of visual ability on learning and memory performance in 13 strains of mice. Learn Mem, 14(3), 134-44. doi:14/3/134 [pii] $10.1101 / 1 \mathrm{~m} .473907$

Cabaj, A. M., \& Slawinska, U. (2012). Riluzole treatment reduces motoneuron death induced by axotomy in newborn rats. J Neurotrauma, 29(7), 1506-17. doi:10.1089/neu.2011.2090

Camp, B. W., Gerson, J. E., Tsang, C. W., Villa, S. R., Acosta, J. I., Blair Braden, B., . . Bimonte-Nelson, H. A. (2012). High serum androstenedione levels correlate with impaired memory in the surgically menopausal rat: A replication and new findings. Eur J Neurosci, 36(8), 3086-95. doi:10.1111/j.1460-9568.2012.08194.x

Carbone, M., Duty, S., \& Rattray, M. (2012). Riluzole neuroprotection in a parkinson's disease model involves suppression of reactive astrocytosis but not GLT-1 regulation. BMC Neurosci, 13, 38. doi:1471-2202-13-38 [pii] 10.1186/1471-2202-13-38

Cheramy, A., Barbeito, L., Godeheu, G., \& Glowinski, J. (1992). Riluzole inhibits the release of glutamate in the caudate nucleus of the cat in vivo. Neurosci Lett, 147(2), 209-12.

Ciobica, A., Olteanu, Z., Padurariu, M., \& Hritcu, L. (2012). The effects of pergolide on memory and oxidative stress in a rat model of parkinson's disease. J Physiol Biochem, 68(1), 59-69. doi:10.1007/s13105-011-0119-x

Corder, E. H., Saunders, A. M., Strittmatter, W. J., Schmechel, D. E., Gaskell, P. C., Small, G. W., . . Pericak-Vance, M. A. (1993). Gene dose of apolipoprotein E type 4 allele and the risk of alzheimer's disease in late onset families. Science, 261(5123), 921-3.

Cotel, M. C., Jawhar, S., Christensen, D. Z., Bayer, T. A., \& Wirths, O. (2012). Environmental enrichment fails to rescue working memory deficits, neuron loss, and neurogenesis in APP/PS1KI mice. Neurobiol Aging, 33(1), 96-107. doi:S0197-4580(10)00090-4 [pii] 10.1016/j.neurobiolaging.2010.02.012 
Crawford, T. J., Higham, S., Mayes, J., Dale, M., Shaunak, S., \& Lekwuwa, G. (2012). The role of working memory and attentional disengagement on inhibitory control: Effects of aging and alzheimer's disease. Age (Dordr), 35(5), 1637-50. doi:10.1007/s11357-012-9466-y

Daniels, R. W., Miller, B. R., \& DiAntonio, A. (2011). Increased vesicular glutamate transporter expression causes excitotoxic neurodegeneration. Neurobiol Dis, 41(2), 415-20. doi:S09699961(10)00343-8 [pii] 10.1016/j.nbd.2010.10.009

Dennis, N. A., Browndyke, J. N., Stokes, J., Need, A., Burke, J. R., Welsh-Bohmer, K. A., \& Cabeza, R. (2010). Temporal lobe functional activity and connectivity in young adult APOE varepsilon4 carriers. Alzheimers Dement, 6(4), 303-11. doi:S1552-5260(09)02093-7 [pii] 10.1016/j.jalz.2009.07.003

DeVos, S. L., Goncharoff, D. K., Chen, G., Kebodeaux, C. S., Yamada, K., Stewart, F. R., . . Miller, T. M. (2013). Antisense reduction of tau in adult mice protects against seizures. $J$ Neurosci, 33(31), 12887-97. doi:33/31/12887 [pii] 10.1523/JNEUROSCI.2107-13.2013

Doody, R. S., Thomas, R. G., Farlow, M., Iwatsubo, T., Vellas, B., Joffe, S., . . Mohs, R. (2014). Phase 3 trials of solanezumab for mild-to-moderate alzheimer's disease. $N$ Engl J Med, 370(4), 311-21. doi:10.1056/NEJMoa1312889

Dutra, R. C., Moreira, E. L., Alberti, T. B., Marcon, R., Prediger, R. D., \& Calixto, J. B. (2013). Spatial reference memory deficits precede motor dysfunction in an experimental autoimmune encephalomyelitis model: The role of kallikrein-kinin system. Brain Behav Immun, 33, 90-101. doi:S0889-1591(13)00226-2 [pii] 10.1016/j.bbi.2013.06.002

Engler-Chiurazzi, E., Tsang, C., Nonnenmacher, S., Liang, W. S., Corneveaux, J. J., Prokai, L., . . . Bimonte-Nelson, H. A. (2011). Tonic premarin dose-dependently enhances memory, affects neurotrophin protein levels and alters gene expression in middle-aged rats. Neurobiol Aging, 32(4), 680-97. doi:S0197-4580(09)00311-X [pii]

10.1016/j.neurobiolaging.2009.09.005

Esclaire, F., Lesort, M., Blanchard, C., \& Hugon, J. (1997). Glutamate toxicity enhances tau gene expression in neuronal cultures. J Neurosci Res, 49(3), 309-18.

doi:10.1002/(SICI)1097-4547(19970801)49:3<309::AID-JNR6>3.0.CO;2-G

Fader, A. J., Johnson, P. E., \& Dohanich, G. P. (1999). Estrogen improves working but not reference memory and prevents amnestic effects of scopolamine of a radial-arm maze. Pharmacol Biochem Behav, 62(4), 711-7. doi:S0091305798002196

Ferrarese, C., Begni, B., Canevari, C., Zoia, C., Piolti, R., Frigo, M., . . Frattola, L. (2000). Glutamate uptake is decreased in platelets from alzheimer's disease patients. Ann Neurol, 47(5), 641-3. 
Frick, K. M., Baxter, M. G., Markowska, A. L., Olton, D. S., \& Price, D. L. (1995). Age-related spatial reference and working memory deficits assessed in the water maze. Neurobiol Aging, 16(2), 149-60. doi:0197458094001553

Frizzo, M. E., Dall'Onder, L. P., Dalcin, K. B., \& Souza, D. O. (2004). Riluzole enhances glutamate uptake in rat astrocyte cultures. Cell Mol Neurobiol, 24(1), 123-8.

Fumagalli, E., Funicello, M., Rauen, T., Gobbi, M., \& Mennini, T. (2008). Riluzole enhances the activity of glutamate transporters GLAST, GLT1 and EAAC1. Eur J Pharmacol, 578(2-3), 171-6. doi:S0014-2999(07)01181-8 [pii] 10.1016/j.ejphar.2007.10.023

Gamoh, S., Hashimoto, M., Sugioka, K., Shahdat Hossain, M., Hata, N., Misawa, Y., \& Masumura, S. (1999). Chronic administration of docosahexaenoic acid improves reference memory-related learning ability in young rats. Neuroscience, 93(1), 237-41. doi:S03064522(99)00107-4

Gourley, S. L., Espitia, J. W., Sanacora, G., \& Taylor, J. R. (2012). Antidepressant-like properties of oral riluzole and utility of incentive disengagement models of depression in mice. Psychopharmacology (Berl), 219(3), 805-14. doi:10.1007/s00213-011-2403-4

Gresack, J. E., \& Frick, K. M. (2003). Male mice exhibit better spatial working and reference memory than females in a water-escape radial arm maze task. Brain Res, 982(1), 98-107. doi:S0006899303030002

Gresack, J. E., \& Frick, K. M. (2006). Effects of continuous and intermittent estrogen treatments on memory in aging female mice. Brain Res, 1115(1), 135-47. doi:S0006-8993(06)02214-1 [pii] 10.1016/j.brainres.2006.07.067

Gruart, A., Lopez-Ramos, J. C., Munoz, M. D., \& Delgado-Garcia, J. M. (2008). Aged wild-type and APP, PS1, and APP + PS1 mice present similar deficits in associative learning and synaptic plasticity independent of amyloid load. Neurobiol Dis, 30(3), 439-50. doi:S09699961(08)00048-X [pii] 10.1016/j.nbd.2008.03.001

Hamberger, A. C., Chiang, G. H., Nylen, E. S., Scheff, S. W., \& Cotman, C. W. (1979). Glutamate as a CNS transmitter. I. evaluation of glucose and glutamine as precursors for the synthesis of preferentially released glutamate. Brain Res, 168(3), 513-30. doi:00068993(79)90306-8

Hardingham, G. E., Fukunaga, Y., \& Bading, H. (2002). Extrasynaptic NMDARs oppose synaptic NMDARs by triggering CREB shut-off and cell death pathways. Nat Neurosci, 5(5), 405-14. doi:10.1038/nn835 [doi] nn835 
Hardy, J. A., \& Higgins, G. A. (1992). Alzheimer's disease: The amyloid cascade hypothesis. Science, 256(5054), 184-5.

Hollmann, M., Hartley, M., \& Heinemann, S. (1991). Ca2+ permeability of KA-AMPA--gated glutamate receptor channels depends on subunit composition. Science, 252(5007), 851-3.

Holmes, C., Boche, D., Wilkinson, D., Yadegarfar, G., Hopkins, V., Bayer, A., . . Nicoll, J. A. (2008). Long-term effects of Abeta42 immunisation in alzheimer's disease: Follow-up of a randomised, placebo-controlled phase I trial. Lancet, 372(9634), 216-23. doi:S01406736(08)61075-2 [pii] 10.1016/S0140-6736(08)61075-2

Hoover, B. R., Reed, M. N., Su, J., Penrod, R. D., Kotilinek, L. A., Grant, M. K., . . Liao, D. (2008). Tau mislocalization to dendritic spines mediates synaptic dysfunction independently of neurodegeneration. Neuron, 68(6), 1067-81. doi:S0896-6273(10)00972-4 [pii] 10.1016/j.neuron.2010.11.030

Huang, Y. (2011). Roles of apolipoprotein E4 (ApoE4) in the pathogenesis of alzheimer's disease: Lessons from ApoE mouse models. Biochem Soc Trans, 39(4), 924-32. doi:BST0390924 [pii] 10.1042/BST0390924

Huijbers, W., Mormino, E. C., Schultz, A. P., Wigman, S., Ward, A. M., Larvie, M., . . Sperling, R. A. (2015). Amyloid-beta deposition in mild cognitive impairment is associated with increased hippocampal activity, atrophy and clinical progression. Brain, 138(Pt 4), 1023-35. doi:awv007 [pii] 10.1093/brain/awv007

Hutton, M., Lendon, C. L., Rizzu, P., Baker, M., Froelich, S., Houlden, H., . . Heutink, P. (1998). Association of missense and 5'-splice-site mutations in tau with the inherited dementia FTDP-17. Nature, 393(6686), 702-5. doi:10.1038/31508

Hyde, L. A., Hoplight, B. J., \& Denenberg, V. H. (1998). Water version of the radial-arm maze: Learning in three inbred strains of mice. Brain Res, 785(2), 236-44. doi:S00068993(97)01417-0

Isaacson, J. S. (1999). Glutamate spillover mediates excitatory transmission in the rat olfactory bulb. Neuron, 23(2), 377-84. doi:S0896-6273(00)80787-4

Jamsa, A., Backstrom, A., Gustafsson, E., Dehvari, N., Hiller, G., Cowburn, R. F., \& Vasange, M. (2006). Glutamate treatment and p 25 transfection increase Cdk5 mediated tau phosphorylation in SH-SY5Y cells. Biochem Biophys Res Commun, 345(1), 324-31. doi:S0006-291X(06)00864-3 [pii] 10.1016/j.bbrc.2006.04.032 
Jarrard, L. E., Okaichi, H., Steward, O., \& Goldschmidt, R. B. (1984). On the role of hippocampal connections in the performance of place and cue tasks: Comparisons with damage to hippocampus. Behav Neurosci, 98(6), 946-54.

Jay, T. M., Zilkha, E., \& Obrenovitch, T. P. (1999). Long-term potentiation in the dentate gyrus is not linked to increased extracellular glutamate concentration. J Neurophysiol, 81(4), 1741-8.

Katsuno, T., Morishima-Kawashima, M., Saito, Y., Yamanouchi, H., Ishiura, S., Murayama, S., \& Ihara, Y. (2005). Independent accumulations of tau and amyloid beta-protein in the human entorhinal cortex. Neurology, 64(4), 687-92. doi:64/4/687 [pii]

10.1212/01.WNL.0000151958.79884.86

Koh, M. T., Haberman, R. P., Foti, S., McCown, T. J., \& Gallagher, M. (2010). Treatment strategies targeting excess hippocampal activity benefit aged rats with cognitive impairment. Neuropsychopharmacology, 35(4), 1016-25. doi:npp2009207 [pii] 10.1038/npp.2009.207

Kril, J. J., Patel, S., Harding, A. J., \& Halliday, G. M. (2002). Neuron loss from the hippocampus of alzheimer's disease exceeds extracellular neurofibrillary tangle formation. Acta Neuropathol, 103(4), 370-6. doi:10.1007/s00401-001-0477-5

Kullmann, D. M., Erdemli, G., \& Asztely, F. (1996). LTP of AMPA and NMDA receptormediated signals: Evidence for presynaptic expression and extrasynaptic glutamate spillover. Neuron, 17(3), 461-74. doi:S0896-6273(00)80178-6

Lamar, M., Podell, K., Carew, T. G., Cloud, B. S., Resh, R., Kennedy, C., . . Libon, D. J. (1997). Perseverative behavior in alzheimer's disease and subcortical ischemic vascular dementia. Neuropsychology, 11(4), 523-34.

Lang, M., Moradi-Chameh, H., Zahid, T., Gane, J., Wu, C., Valiante, T., \& Zhang, L. (2014). Regulating hippocampal hyperexcitability through GABAB receptors. Physiol Rep, 2(4), e00278. doi:2/4/e00278 [pii] 10.14814/phy2.278

Levenga, J., Krishnamurthy, P., Rajamohamedsait, H., Wong, H., Franke, T. F., Cain, P., . . Hoeffer, C. A. (2013). Tau pathology induces loss of GABAergic interneurons leading to altered synaptic plasticity and behavioral impairments. Acta Neuropathol Commun, 1(1), 34. doi:2051-5960-1-34 [pii] 10.1186/2051-5960-1-34

Li, K., \& Xu, E. (2008). The role and the mechanism of gamma-aminobutyric acid during central nervous system development. Neurosci Bull, 24(3), 195-200. 
Li, Z., Hall, A. M., Kelinske, M., \& Roberson, E. D. (2014). Seizure resistance without parkinsonism in aged mice after tau reduction. Neurobiol Aging, 35(11), 2617-24. doi:S0197-4580(14)00339-X [pii] 10.1016/j.neurobiolaging.2014.05.001

Liepert, J., Schwenkreis, P., Tegenthoff, M., \& Malin, J. P. (1997). The glutamate antagonist riluzole suppresses intracortical facilitation. J Neural Transm, 104(11-12), 1207-14.

Lieth, E., LaNoue, K. F., Berkich, D. A., Xu, B., Ratz, M., Taylor, C., \& Hutson, S. M. (2001). Nitrogen shuttling between neurons and glial cells during glutamate synthesis. $J$ Neurochem, 76(6), 1712-23.

Lockrow, J., Boger, H., Bimonte-Nelson, H., \& Granholm, A. C. (2011). Effects of long-term memantine on memory and neuropathology in Ts65Dn mice, a model for down syndrome. Behav Brain Res, 221(2), 610-22. doi:S0166-4328(10)00222-6 [pii] 10.1016/j.bbr.2010.03.036

Lu, W., Man, H., Ju, W., Trimble, W. S., MacDonald, J. F., \& Wang, Y. T. (2001). Activation of synaptic NMDA receptors induces membrane insertion of new AMPA receptors and LTP in cultured hippocampal neurons. Neuron, 29(1), 243-54. doi:S0896-6273(01)00194-5

Malgouris, C., Bardot, F., Daniel, M., Pellis, F., Rataud, J., Uzan, A., . . Laduron, P. M. (1989). Riluzole, a novel antiglutamate, prevents memory loss and hippocampal neuronal damage in ischemic gerbils. J Neurosci, 9(11), 3720-7.

Mazzone, G. L., \& Nistri, A. (2011). Delayed neuroprotection by riluzole against excitotoxic damage evoked by kainate on rat organotypic spinal cord cultures. Neuroscience, 190, 31827. doi:S0306-4522(11)00697-X [pii] 10.1016/j.neuroscience.2011.06.013

Miller, R. G., Mitchell, J. D., \& Moore, D. H. (2012). Riluzole for amyotrophic lateral sclerosis (ALS)/motor neuron disease (MND). Cochrane Database Syst Rev, 3, CD001447. doi:10.1002/14651858.CD001447.pub3

Mladin, C., Ciobica, A., Lefter, R., Popescu, A., \& Bild, W. (2014). Deuterium-depleted water has stimulating effects on long-term memory in rats. Neurosci Lett, 583, 154-8. doi:S03043940(14)00774-5 [pii] 10.1016/j.neulet.2014.09.037

Mustroph, M. L., King, M. A., Klein, R. L., \& Ramirez, J. J. (2012). Adult-onset focal expression of mutated human tau in the hippocampus impairs spatial working memory of rats. Behav Brain Res, 233(1), 141-8. doi:S0166-4328(12)00295-1 [pii]

10.1016/j.bbr.2012.04.034 
Nhan, H. S., Chiang, K., \& Koo, E. H. (2015). The multifaceted nature of amyloid precursor protein and its proteolytic fragments: Friends and foes. Acta Neuropathol, 129(1), 1-19. doi:10.1007/s00401-014-1347-2

Nieto-Gonzalez, J. L., Moser, J., Lauritzen, M., Schmitt-John, T., \& Jensen, K. (2011). Reduced GABAergic inhibition explains cortical hyperexcitability in the wobbler mouse model of ALS. Cereb Cortex, 21(3), 625-35. doi:bhq134 [pii] 10.1093/cercor/bhq134

Niewoehner, B., Single, F. N., Hvalby, O., Jensen, V., Meyer zum Alten Borgloh, S., Seeburg, P. H., . . Bannerman, D. M. (2007). Impaired spatial working memory but spared spatial reference memory following functional loss of NMDA receptors in the dentate gyrus. Eur $J$ Neurosci, 25(3), 837-46. doi:EJN5312 [pii] 10.1111/j.1460-9568.2007.05312.x

Oddo, S., Billings, L., Kesslak, J. P., Cribbs, D. H., \& LaFerla, F. M. (2004). Abeta immunotherapy leads to clearance of early, but not late, hyperphosphorylated tau aggregates via the proteasome. Neuron, 43(3), 321-32. doi:10.1016/j.neuron.2004.07.003 [doi] S0896627304004246

Olmos-Serrano, J. L., Paluszkiewicz, S. M., Martin, B. S., Kaufmann, W. E., Corbin, J. G., \& Huntsman, M. M. (2010). Defective GABAergic neurotransmission and pharmacological rescue of neuronal hyperexcitability in the amygdala in a mouse model of fragile $\mathrm{X}$ syndrome. J Neurosci, 30(29), 9929-38. doi:30/29/9929 [pii] 10.1523/JNEUROSCI.171410.2010

Pearson, R. C., Esiri, M. M., Hiorns, R. W., Wilcock, G. K., \& Powell, T. P. (1985). Anatomical correlates of the distribution of the pathological changes in the neocortex in alzheimer disease. Proc Natl Acad Sci US A, 82(13), 4531-4.

Pennanen, L., Wolfer, D. P., Nitsch, R. M., \& Gotz, J. (2006). Impaired spatial reference memory and increased exploratory behavior in P301L tau transgenic mice. Genes Brain Behav, 5(5), 369-79. doi:GBB165 [pii] 10.1111/j.1601-183X.2005.00165.x

Pitt, D., Nagelmeier, I. E., Wilson, H. C., \& Raine, C. S. (2003). Glutamate uptake by oligodendrocytes: Implications for excitotoxicity in multiple sclerosis. Neurology, 61(8), 1113-20.

Ramsden, M., Kotilinek, L., Forster, C., Paulson, J., McGowan, E., SantaCruz, K., .. . Ashe, K. H. (2005). Age-dependent neurofibrillary tangle formation, neuron loss, and memory impairment in a mouse model of human tauopathy (P301L). J Neurosci, 25(46), 10637-47. doi:25/46/10637 [pii] 10.1523/JNEUROSCI.3279-05.2005 
Reisberg, B., Doody, R., Stoffler, A., Schmitt, F., Ferris, S., \& Mobius, H. J. (2003). Memantine in moderate-to-severe alzheimer's disease. N Engl J Med, 348(14), 1333-41. doi:10.1056/NEJMoa013128 [doi] 348/14/1333

Reisel, D., Bannerman, D. M., Schmitt, W. B., Deacon, R. M., Flint, J., Borchardt, T., . . . Rawlins, J. N. (2002). Spatial memory dissociations in mice lacking GluR1. Nat Neurosci, 5(9), 868-73. doi:10.1038/nn910 [doi] nn910

Roberson, E. D., Halabisky, B., Yoo, J. W., Yao, J., Chin, J., Yan, F., . . Mucke, L. (2011). Amyloid-beta/Fyn-induced synaptic, network, and cognitive impairments depend on tau levels in multiple mouse models of alzheimer's disease. J Neurosci, 31(2), 700-11. doi:31/2/700 [pii] 10.1523/JNEUROSCI.4152-10.2011

Roberson, E. D., Scearce-Levie, K., Palop, J. J., Yan, F., Cheng, I. H., Wu, T., . . Mucke, L. (2007). Reducing endogenous tau ameliorates amyloid beta-induced deficits in an alzheimer's disease mouse model. Science, 316(5825), 750-4. doi:316/5825/750 [pii] $10.1126 /$ science. 1141736

Salat, D. H., Tuch, D. S., van der Kouwe, A. J., Greve, D. N., Pappu, V., Lee, S. Y., . . Rosas, H. D. (2010). White matter pathology isolates the hippocampal formation in alzheimer's disease. Neurobiol Aging, 31(2), 244-56. doi:S0197-4580(08)00104-8 [pii] 10.1016/j.neurobiolaging.2008.03.013

Sanchez, P. E., Zhu, L., Verret, L., Vossel, K. A., Orr, A. G., Cirrito, J. R., . . Mucke, L. (2012). Levetiracetam suppresses neuronal network dysfunction and reverses synaptic and cognitive deficits in an alzheimer's disease model. Proc Natl Acad Sci U S A, 109(42), E2895-903. doi:1121081109 [pii] 10.1073/pnas.1121081109

Sannino, S., Russo, F., Torromino, G., Pendolino, V., Calabresi, P., \& De Leonibus, E. (2012). Role of the dorsal hippocampus in object memory load. Learn Mem, 19(5), 211-8. doi:19/5/211 [pii] 10.1101/1m.025213.111

Santacruz, K., Lewis, J., Spires, T., Paulson, J., Kotilinek, L., Ingelsson, M., . . Ashe, K. H. (2005). Tau suppression in a neurodegenerative mouse model improves memory function. Science, 309(5733), 476-81. doi:309/5733/476 [pii] 10.1126/science.1113694

Schenk, D., Barbour, R., Dunn, W., Gordon, G., Grajeda, H., Guido, T., . . Seubert, P. (1999). Immunization with amyloid-beta attenuates alzheimer-disease-like pathology in the PDAPP mouse. Nature, 400(6740), 173-7. doi:10.1038/22124

Schmitt, W. B., Deacon, R. M., Seeburg, P. H., Rawlins, J. N., \& Bannerman, D. M. (2003). A within-subjects, within-task demonstration of intact spatial reference memory and impaired 
spatial working memory in glutamate receptor-A-deficient mice. $J$ Neurosci, 23(9), 3953-9. doi:23/9/3953

Sharma, G., \& Vijayaraghavan, S. (2003). Modulation of presynaptic store calcium induces release of glutamate and postsynaptic firing. Neuron, 38(6), 929-39. doi:S0896627303003222

Shukitt-Hale, B., McEwen, J. J., Szprengiel, A., \& Joseph, J. A. (2004). Effect of age on the radial arm water maze-a test of spatial learning and memory. Neurobiol Aging, 25(2), 223-9. doi:S0197458003000411

Sibson, N. R., Dhankhar, A., Mason, G. F., Behar, K. L., Rothman, D. L., \& Shulman, R. G. (1997). In vivo 13C NMR measurements of cerebral glutamine synthesis as evidence for glutamate-glutamine cycling. Proc Natl Acad Sci U S A, 94(6), 2699-704.

Son, J. H., Kuhn, J., \& Keefe, K. A. (2013). Perseverative behavior in rats with methamphetamine-induced neurotoxicity. Neuropharmacology, 67, 95-103. doi:S00283908(12)00523-0 [pii] 10.1016/j.neuropharm.2012.09.021

Sonnewald, U., Westergaard, N., \& Schousboe, A. (1997). Glutamate transport and metabolism in astrocytes. Glia, 21(1), 56-63. doi:10.1002/(SICI)1098-1136(199709)21:1<56::AIDGLIA6>3.0.CO;2-\#

Spires, T. L., Orne, J. D., SantaCruz, K., Pitstick, R., Carlson, G. A., Ashe, K. H., \& Hyman, B. T. (2006). Region-specific dissociation of neuronal loss and neurofibrillary pathology in a mouse model of tauopathy. Am J Pathol, 168(5), 1598-607. doi:S0002-9440(10)62182-7 [pii] 10.2353/ajpath.2006.050840

Stephan, A., Laroche, S., \& Davis, S. (2001). Generation of aggregated beta-amyloid in the rat hippocampus impairs synaptic transmission and plasticity and causes memory deficits. $J$ Neurosci, 21(15), 5703-14. doi:21/15/5703

Stopford, C. L., Thompson, J. C., Neary, D., Richardson, A. M., \& Snowden, J. S. (2012). Working memory, attention, and executive function in alzheimer's disease and frontotemporal dementia. Cortex, 48(4), 429-46. doi:S0010-9452(10)00299-6 [pii] 10.1016/j.cortex.2010.12.002

Sugiyama, A., Saitoh, A., Iwai, T., Takahashi, K., Yamada, M., Sasaki-Hamada, S., ... Inagaki, M. (2012). Riluzole produces distinct anxiolytic-like effects in rats without the adverse effects associated with benzodiazepines. Neuropharmacology, 62(8), 2489-98. doi:S00283908(12)00073-1 [pii] 10.1016/j.neuropharm.2012.02.012 
Tackenberg, C., Grinschgl, S., Trutzel, A., Santuccione, A. C., Frey, M. C., Konietzko, U., . . Nitsch, R. M. (2013). NMDA receptor subunit composition determines beta-amyloidinduced neurodegeneration and synaptic loss. Cell Death Dis, 4, e608. doi:cddis2013129 [pii] 10.1038/cddis.2013.129

Tanzi, R. E., Gusella, J. F., Watkins, P. C., Bruns, G. A., St George-Hyslop, P., Van Keuren, M. L., . . Neve, R. L. (1987). Amyloid beta protein gene: CDNA, mRNA distribution, and genetic linkage near the alzheimer locus. Science, 235(4791), 880-4.

Urbani, A., \& Belluzzi, O. (2000). Riluzole inhibits the persistent sodium current in mammalian CNS neurons. Eur J Neurosci, 12(10), 3567-74. doi:ejn242

Verhave, P. S., Jongsma, M. J., Van Den Berg, R. M., Vanwersch, R. A., Smit, A. B., \& Philippens, I. H. (2012). Neuroprotective effects of riluzole in early phase parkinson's disease on clinically relevant parameters in the marmoset MPTP model. Neuropharmacology, 62(4), 1700-7. doi:S0028-3908(11)00495-3 [pii] 10.1016/j.neuropharm.2011.11.016

Vossel, K. A., Beagle, A. J., Rabinovici, G. D., Shu, H., Lee, S. E., Naasan, G., . . Mucke, L. (2013). Seizures and epileptiform activity in the early stages of alzheimer disease. JAMA Neurol, 70(9), 1158-66. doi:1709572 [pii] 10.1001/jamaneurol.2013.136

Wang, S. J., Wang, K. Y., \& Wang, W. C. (2004). Mechanisms underlying the riluzole inhibition of glutamate release from rat cerebral cortex nerve terminals (synaptosomes). Neuroscience, 125(1), 191-201. doi:10.1016/j.neuroscience.2004.01.019 [doi] S0306452204000569

Warmus, B. A., Sekar, D. R., McCutchen, E., Schellenberg, G. D., Roberts, R. C., McMahon, L. L., \& Roberson, E. D. (2014). Tau-mediated NMDA receptor impairment underlies dysfunction of a selectively vulnerable network in a mouse model of frontotemporal dementia. J Neurosci, 34(49), 16482-95. doi:34/49/16482 [pii] 10.1523/JNEUROSCI.341814.2014

Weingarten, M. D., Lockwood, A. H., Hwo, S. Y., \& Kirschner, M. W. (1975). A protein factor essential for microtubule assembly. Proc Natl Acad Sci U S A, 72(5), 1858-62.

Wojcik, S. M., Rhee, J. S., Herzog, E., Sigler, A., Jahn, R., Takamori, S., . . Rosenmund, C. (2004). An essential role for vesicular glutamate transporter 1 (VGLUT1) in postnatal development and control of quantal size. Proc Natl Acad Sci U S A, 101(18), 7158-63. doi:10.1073/pnas.0401764101 [doi] 0401764101

Xu, L., Enyeart, J. A., \& Enyeart, J. J. (2001). Neuroprotective agent riluzole dramatically slows inactivation of Kv1.4 potassium channels by a voltage-dependent oxidative mechanism. $J$ Pharmacol Exp Ther, 299(1), 227-37. 
Zago, W., Buttini, M., Comery, T. A., Nishioka, C., Gardai, S. J., Seubert, P., . . Kinney, G. G. (2012). Neutralization of soluble, synaptotoxic amyloid beta species by antibodies is epitope specific. J Neurosci, 32(8), 2696-702. doi:32/8/2696 [pii] 10.1523/JNEUROSCI.167611.2012 


A \begin{tabular}{|c|c|c|}
\hline Controls & \multicolumn{2}{|c|}{ TauP301L } \\
\hline Vehicle & Vehicle & Riluzole \\
\hline 23 & 24 & 21 \\
\hline
\end{tabular}
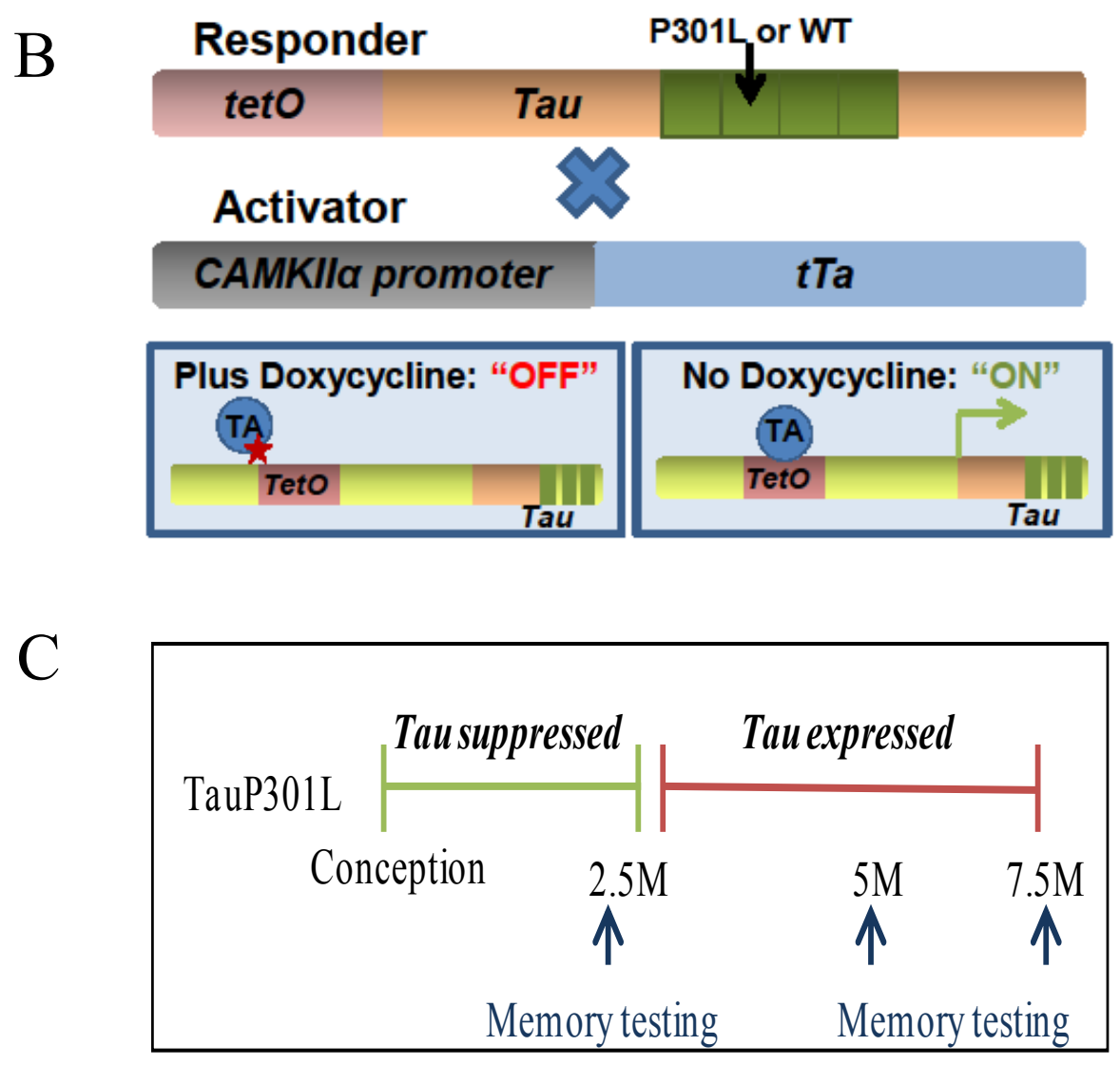

Figure 1. Design of study. (A) There were a total of 68 mice in the experiment, with a range of 21 to 24 mice in each group. (B) Tau P301L responder lines encode for human 4-repeat tau lacking the amino-terminal sequence $(4 \mathrm{R} 0 \mathrm{~N})$. The activator line uses the CaMKII $\alpha$ promoter to restrict expression to the forebrain. The tTA binds to the tetO promoter to initiate transcription, leading to production of the tau protein. (C) Tau expression was suppressed using doxycycline hyclate (40 ppm) until 2.5 months of age. Mice were tested at 2.5, 5, and 7.5 months of age. 


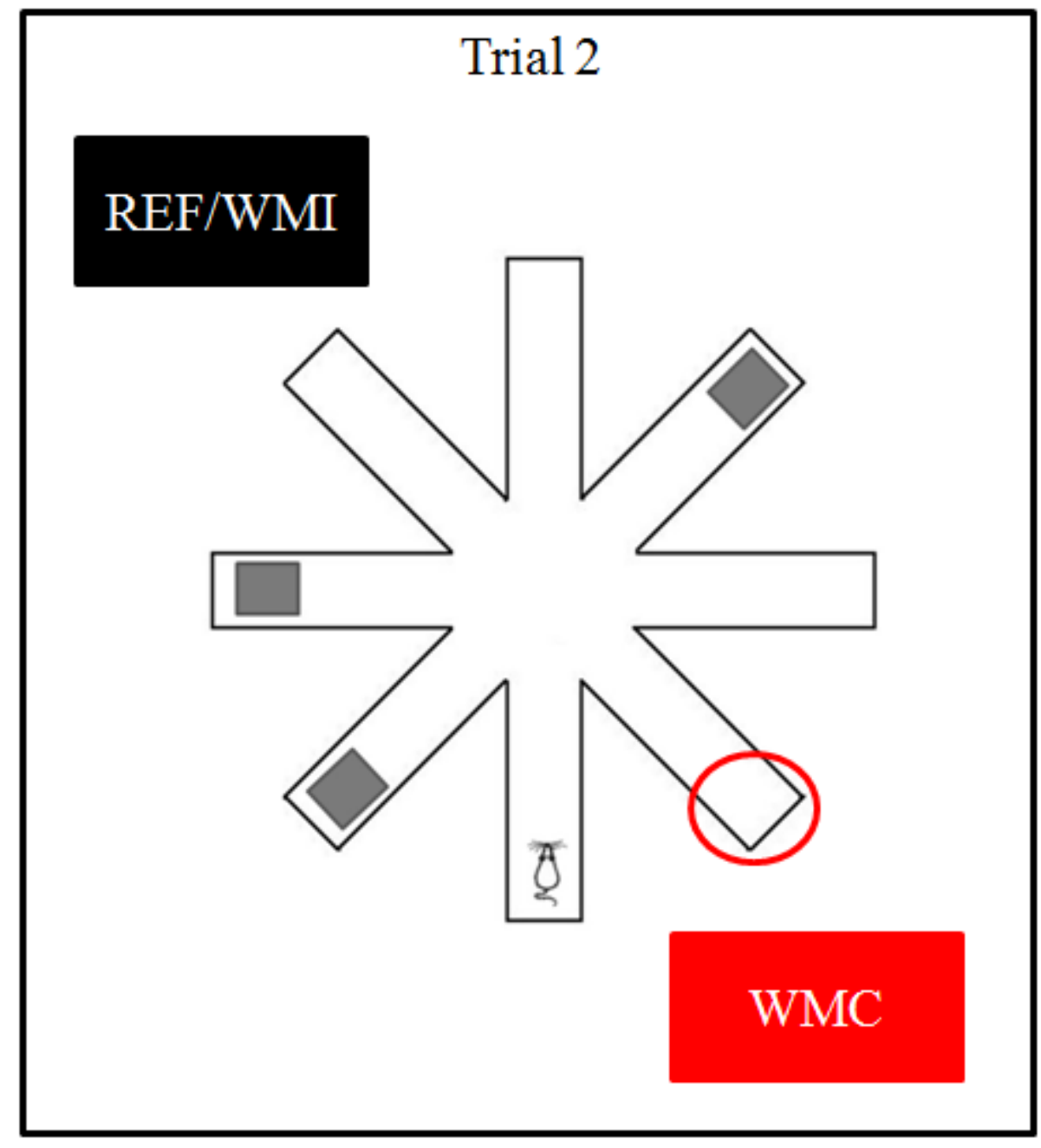

Figure 2. Visual representation of errors on WRAM test. Following being released from the start point on trial 2, entrance into an arm which previously contained a platform (represented by the red circle) results in a working memory correct error (WMC). Entrance into an arm which never contained a platform is considered a reference memory error (REF). Re-entry into an arm which never contained a platform results in a working memory incorrect error (WMI). Thus, a WMI is a repeated REF error. 

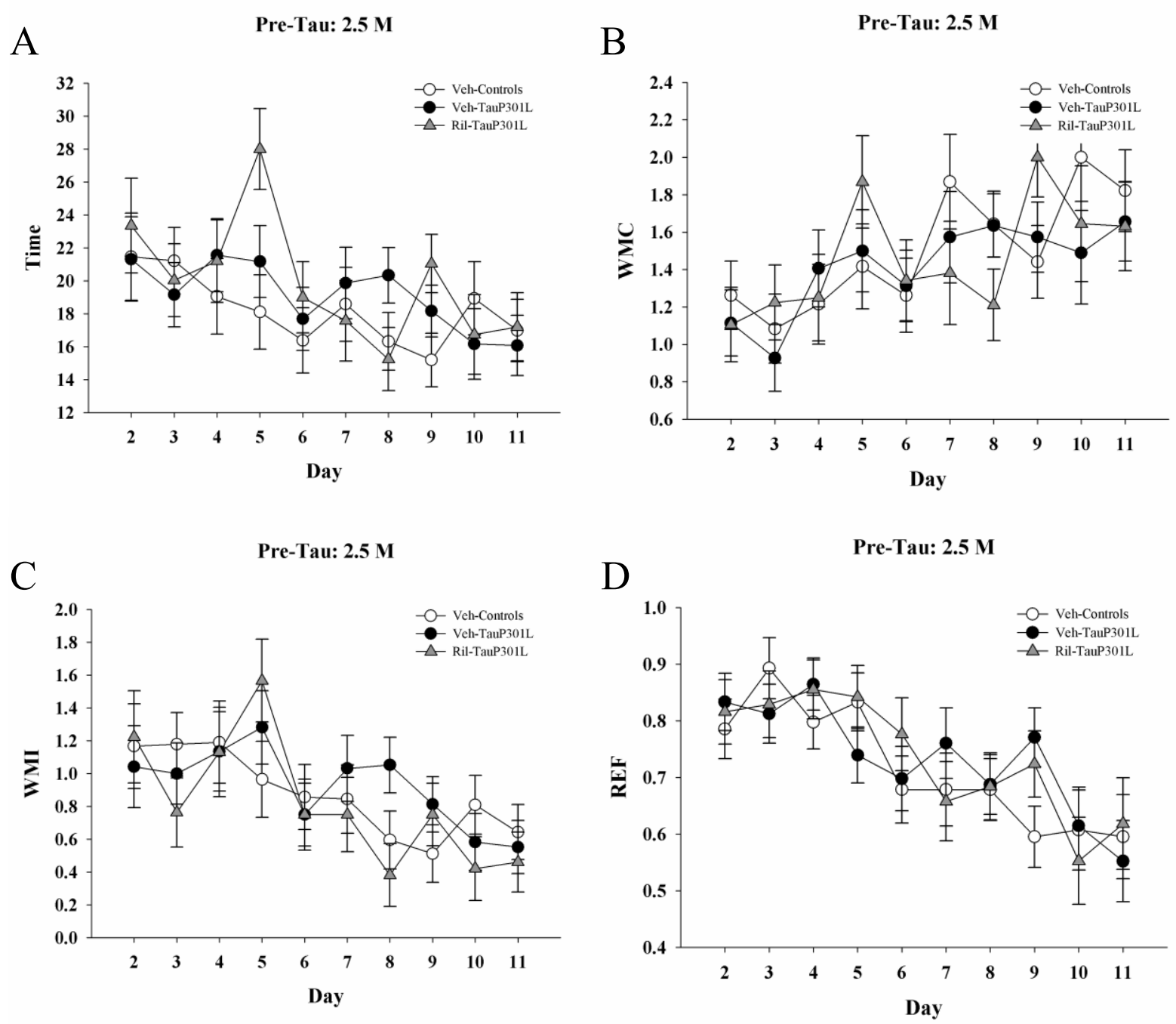

Figure 3. Similar performance among Groups prior to tau expression. There were no differences among the Groups for time (A), WMC (B), WMI (C), or REF errors (D) during acquisition at 2.5 months of age, prior to the expression of tau $(p s>.10)$. There were Day effects for time $(p$ $=.0005), \mathrm{WMC}(p=.0006), \mathrm{WMI}(p<.0001)$, and REF errors $(p<.0001)$. 


\section{Pre-Tau: $2.5 \mathrm{M}$}

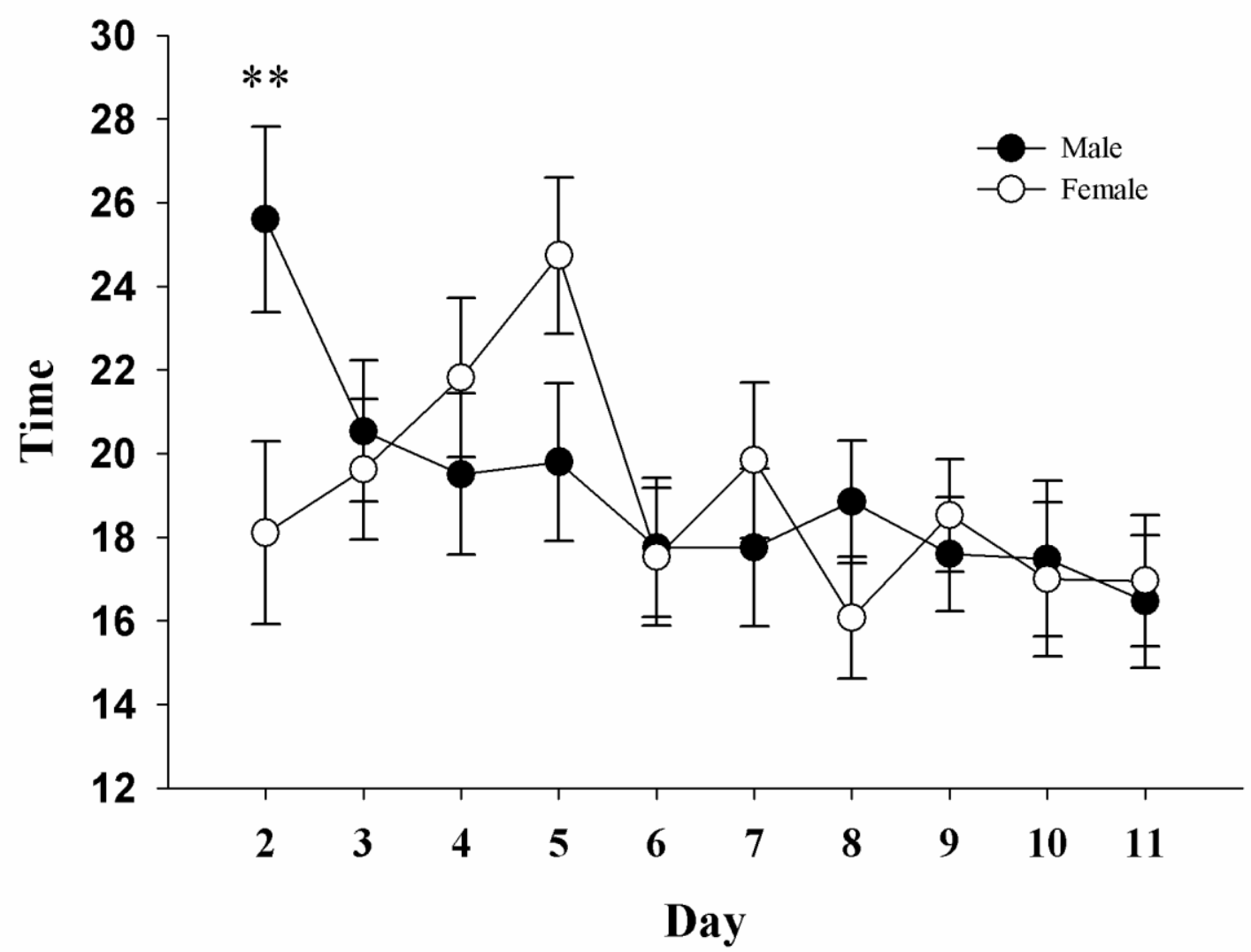

Figure 4. Sex differences in time to locate the platform prior to tau expression. There was a significant Day*Sex interaction for time during acquisition at 2.5 months of age $(p=.04)$. (** $\mathrm{p}<.01)$ 


\section{Pre-Tau: $2.5 \mathrm{M}$}

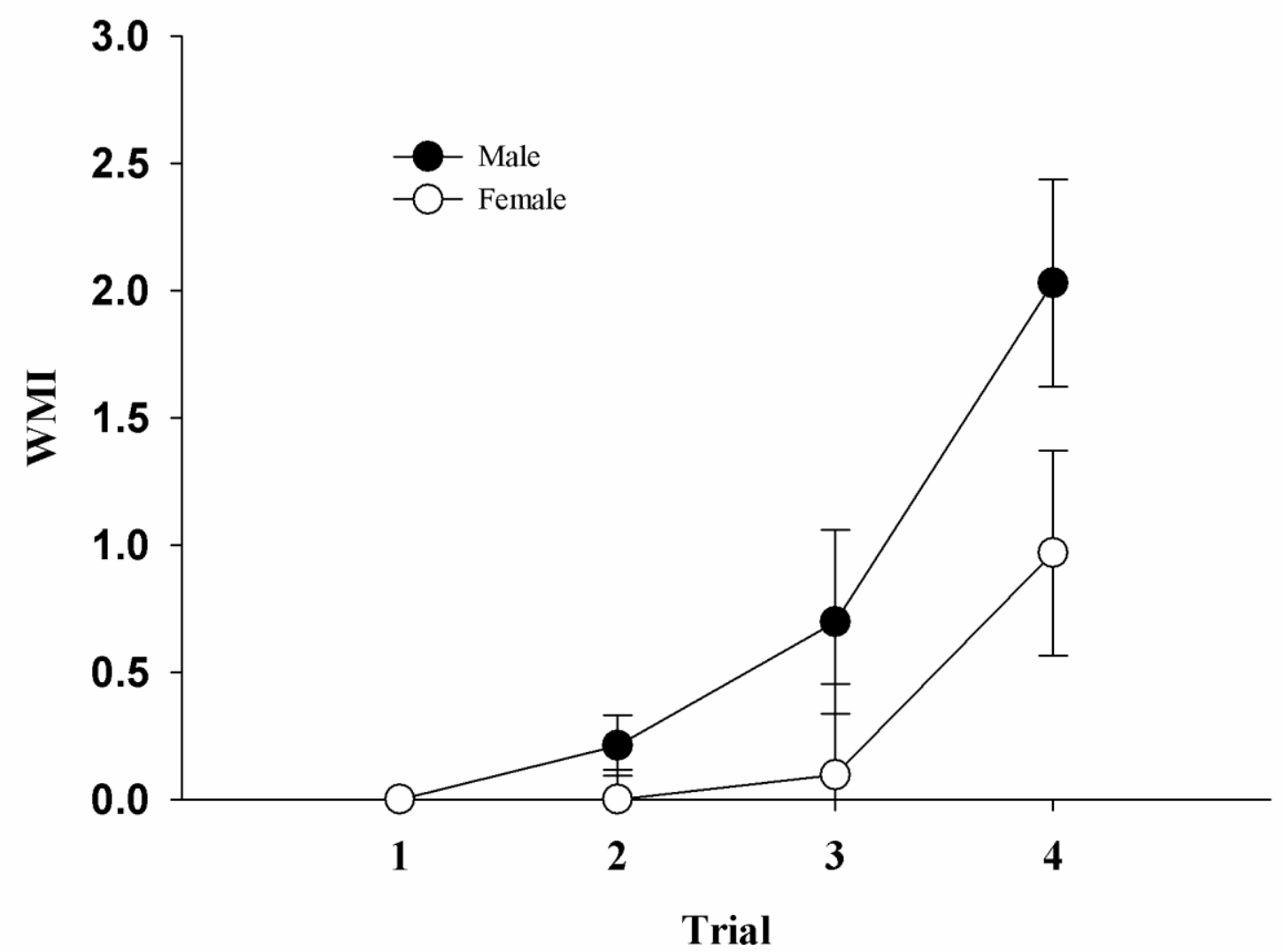

Figure 5. Male mice make more errors prior to tau expression. With the insertion of a 4-hour delay, male mice made significantly more WMI errors than female mice on day 12 at 2.5 months of age $(p=.05)$. 

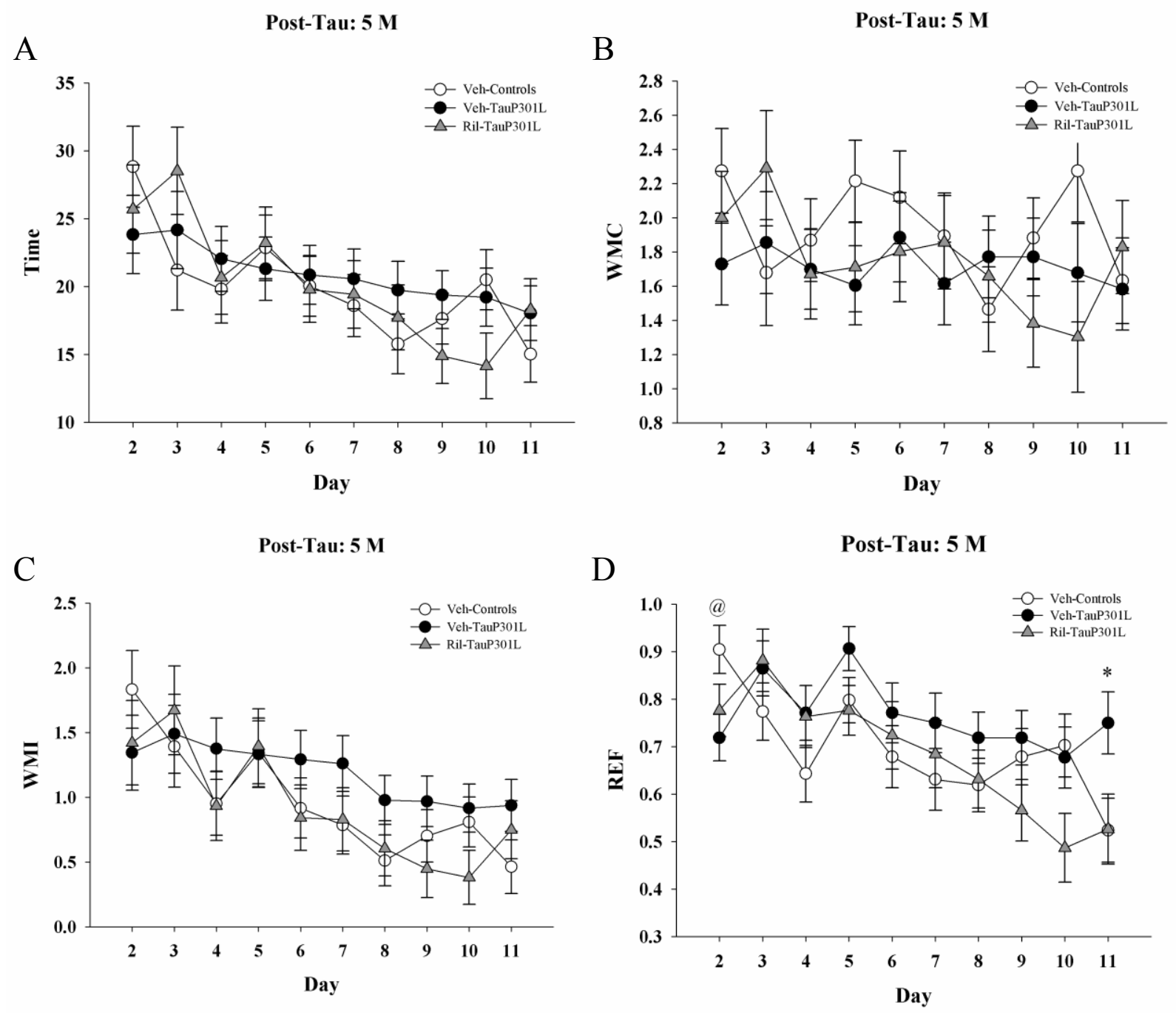

Figure 6. Veh-TauP301L mice exhibit deficits during acquisition at 5 months of age, 2.5 months post-tau expression. There were significant effects of Day for time, WMI, and REF $(p s<.0001)$. A significant Day*Group interaction for REF errors was observed $(\mathrm{p}<.05)$ where Veh-Controls and Ril-TauP301L improved in REF performance with additional training $(p \mathrm{~s}<.0001)$ while Veh-TauP301L mice did not $(p=.12)$ (D). ( * p <.05 Veh-Controls vs. Veh-TauP301L, @ $\mathrm{p}<.01$ Veh-TauP301L vs. Veh-Controls). 
A

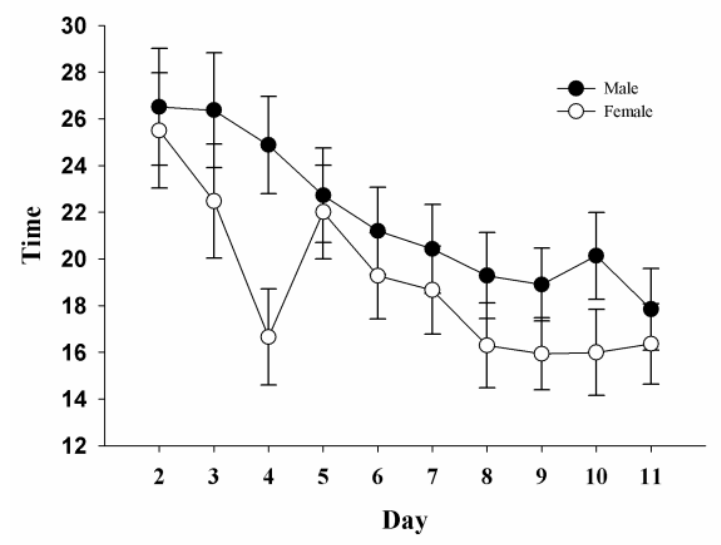

C

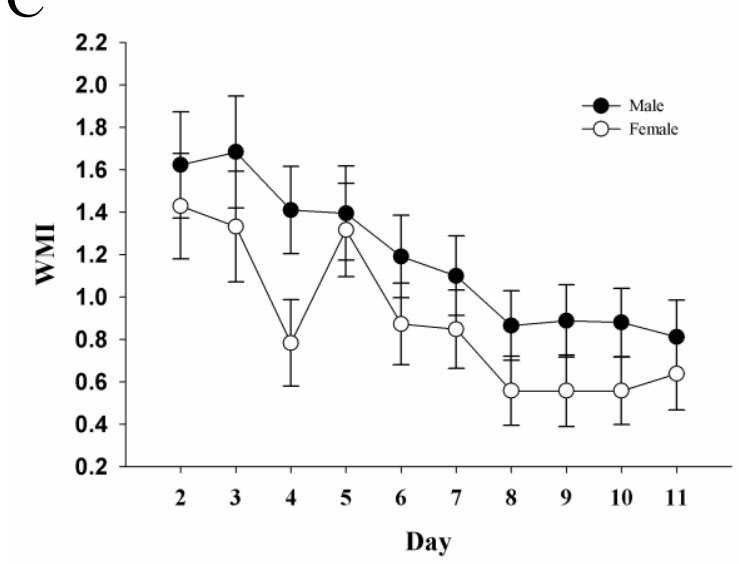

$\mathrm{B}$
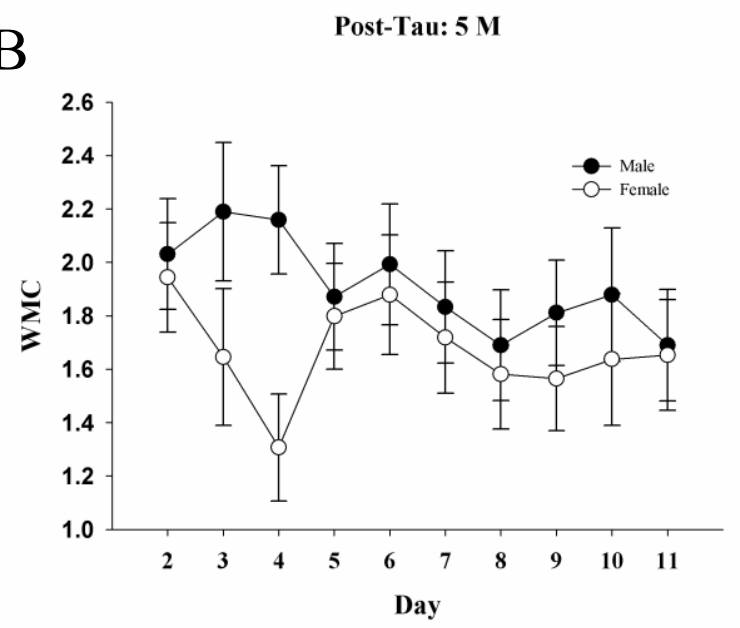

$\mathrm{D}$

Post-Tau: 5 M

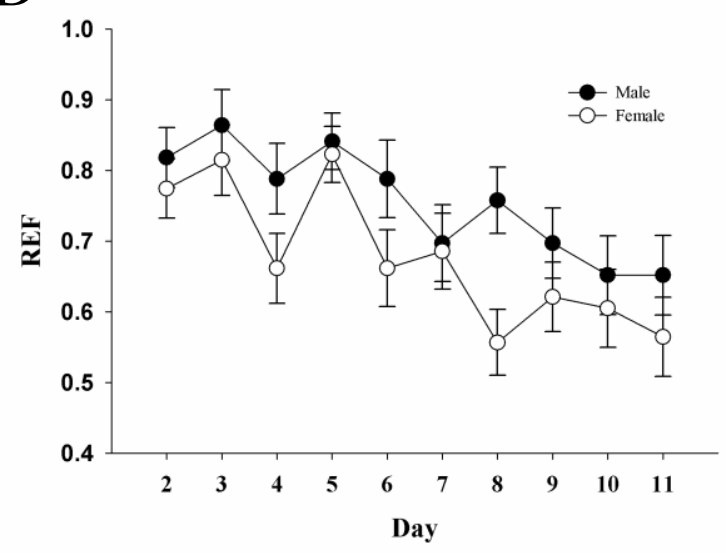

Figure 7. Sex differences during acquisition at 5 months of age. During acquisition, male mice took more time $(p=.02)$ to locate the platforms $(\mathrm{A})$, and made more WMC $(p=.04)(\mathrm{B})$, WMI $(p$ $=.03)(\mathrm{C})$ and REF errors $(p=.02)(\mathrm{D})$ at 5 months of age, 2.5 months post-tau expression. 
A

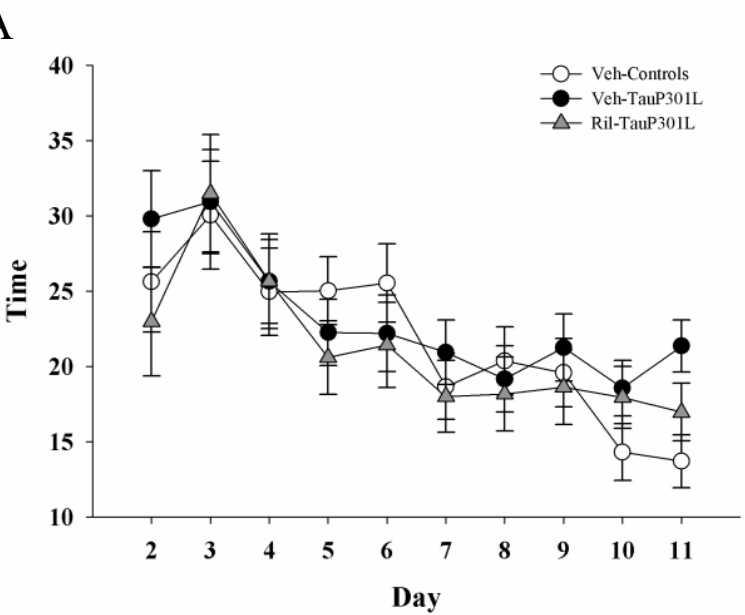

$\mathrm{C}$

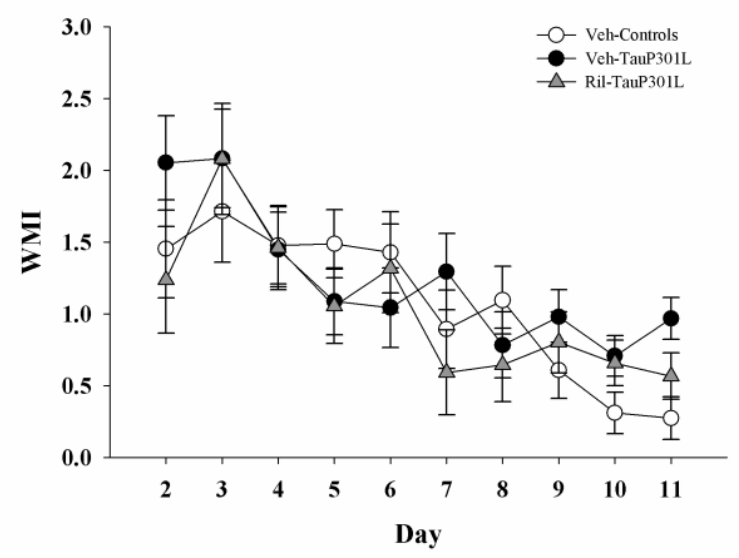

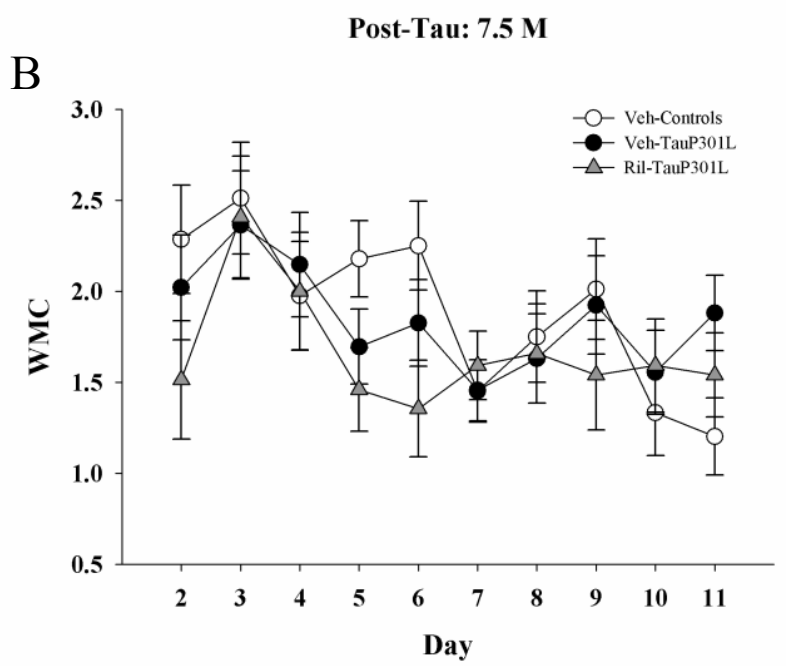

$\mathrm{D}$

Post-Tau: $7.5 \mathrm{M}$

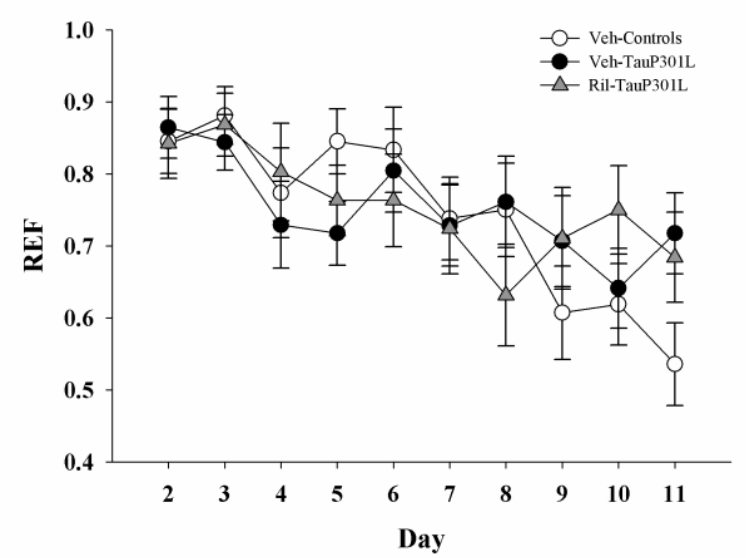

Figure 8. Similar performance during acquisition at 7.5 months of age. There were significant Day effects for time (A), WMC (B), WMI (C), and REF errors (D) ( $p$ s $<.0001)$, where performance improved with additional training at 7.5 months of age, 5 months post-tau expression. 


\section{Post-Tau: 5 M}

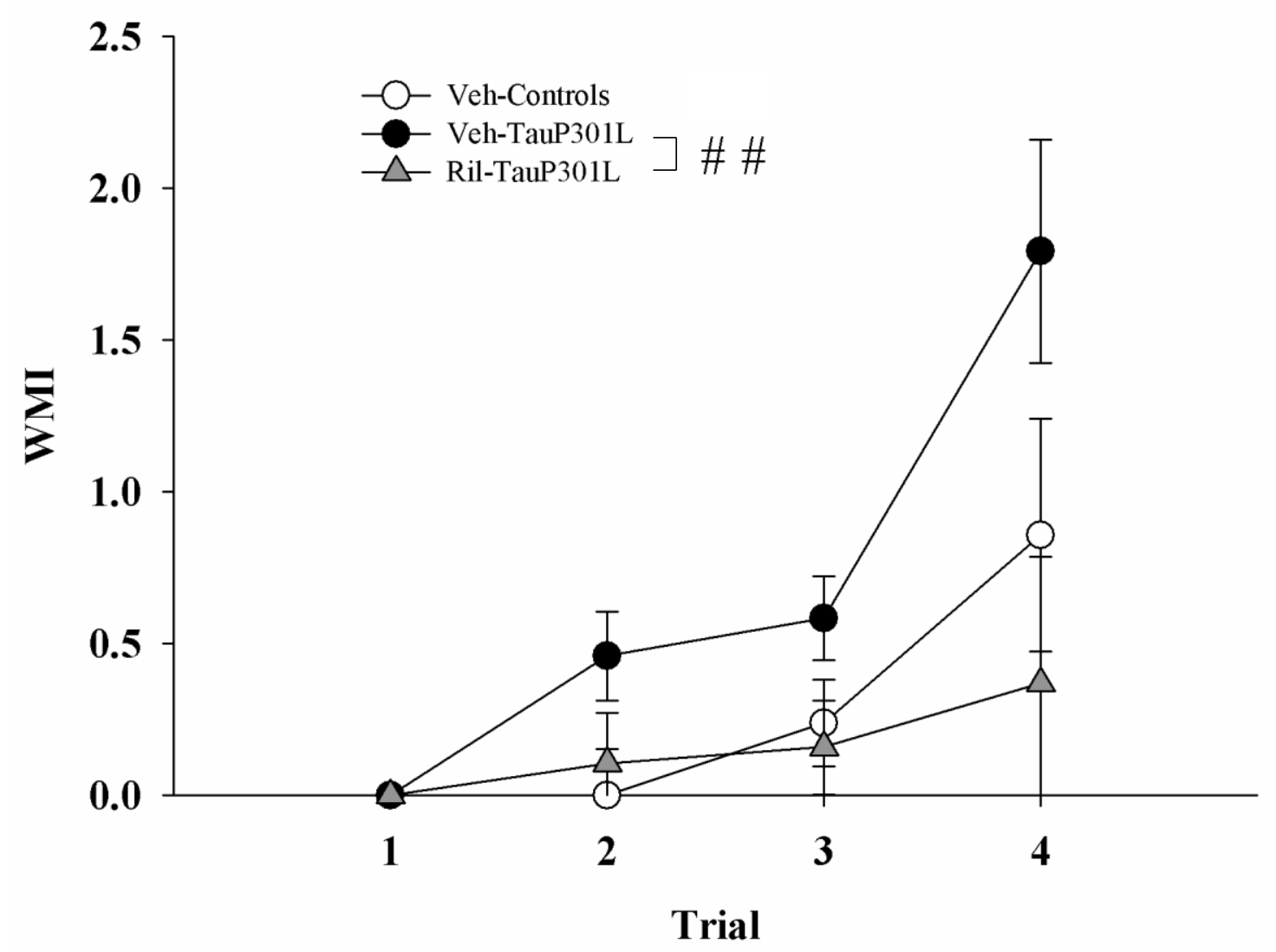

Figure 9. Riluzole attenuates memory deficits in TauP301L mice at 5 months of age. During Day 13 with the 6-hour delay at 5 months of age, 2.5 months post tau expression, Veh-TauP301L made significantly more WMI errors $(p=.0007)$. (\# \# $p<.01$ Ril-TauP301L vs. Veh-TauP301L). 


\section{Post-Tau: 7.5 M}

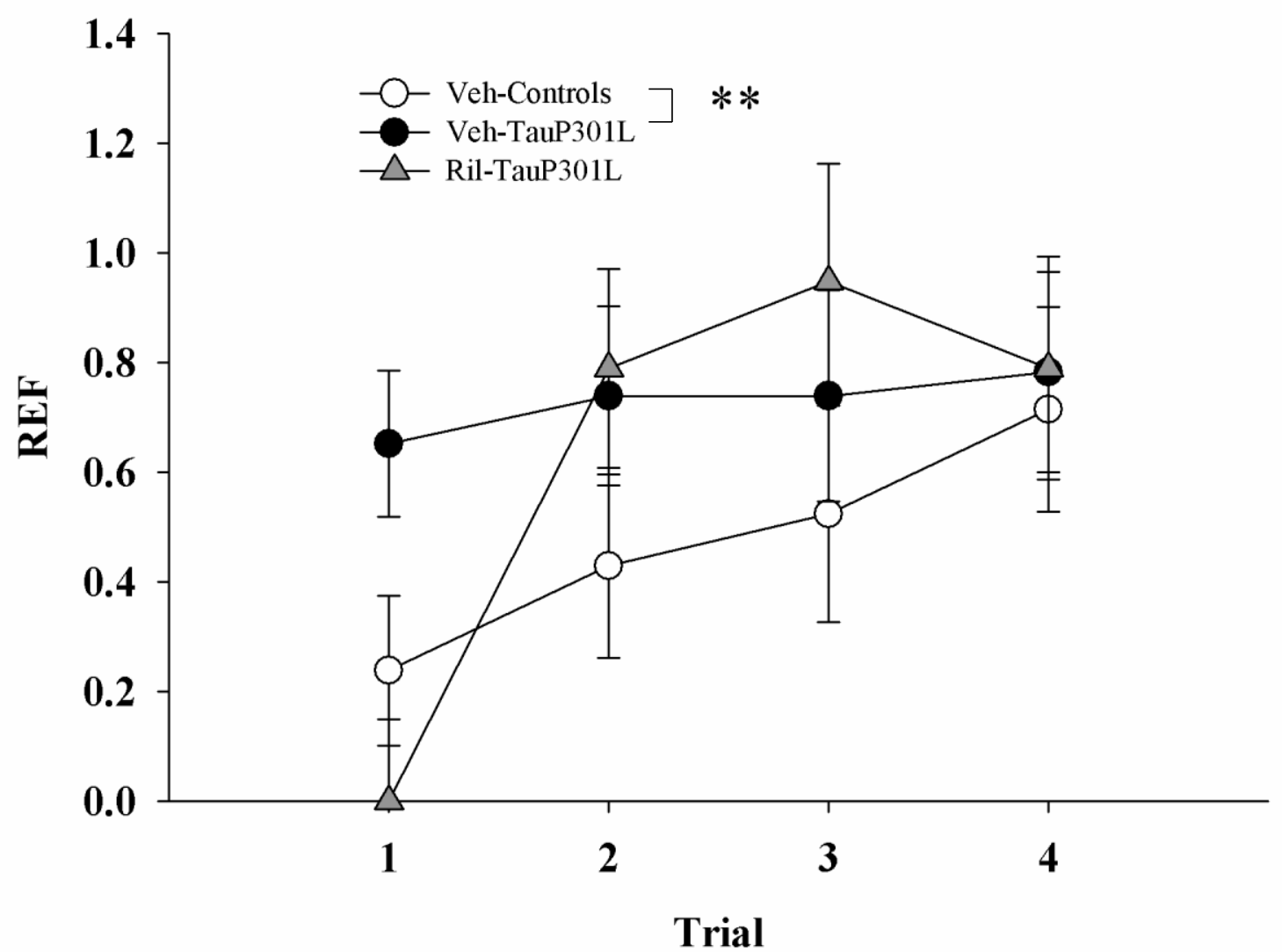

Figure 10. Veh-TauP301L show impairments at 7.5 months of age. During Day 12 with a 4-hour delay at 7.5 months of age, 5 months post-tau expression, Veh-TauP301L mice made more REF as compared to Veh-Controls $(p=.01) .\left({ }^{* *} \mathrm{p}<.01\right.$ Veh-Controls vs. Veh-TauP301L). 


\section{Post-Tau: 7.5 M}

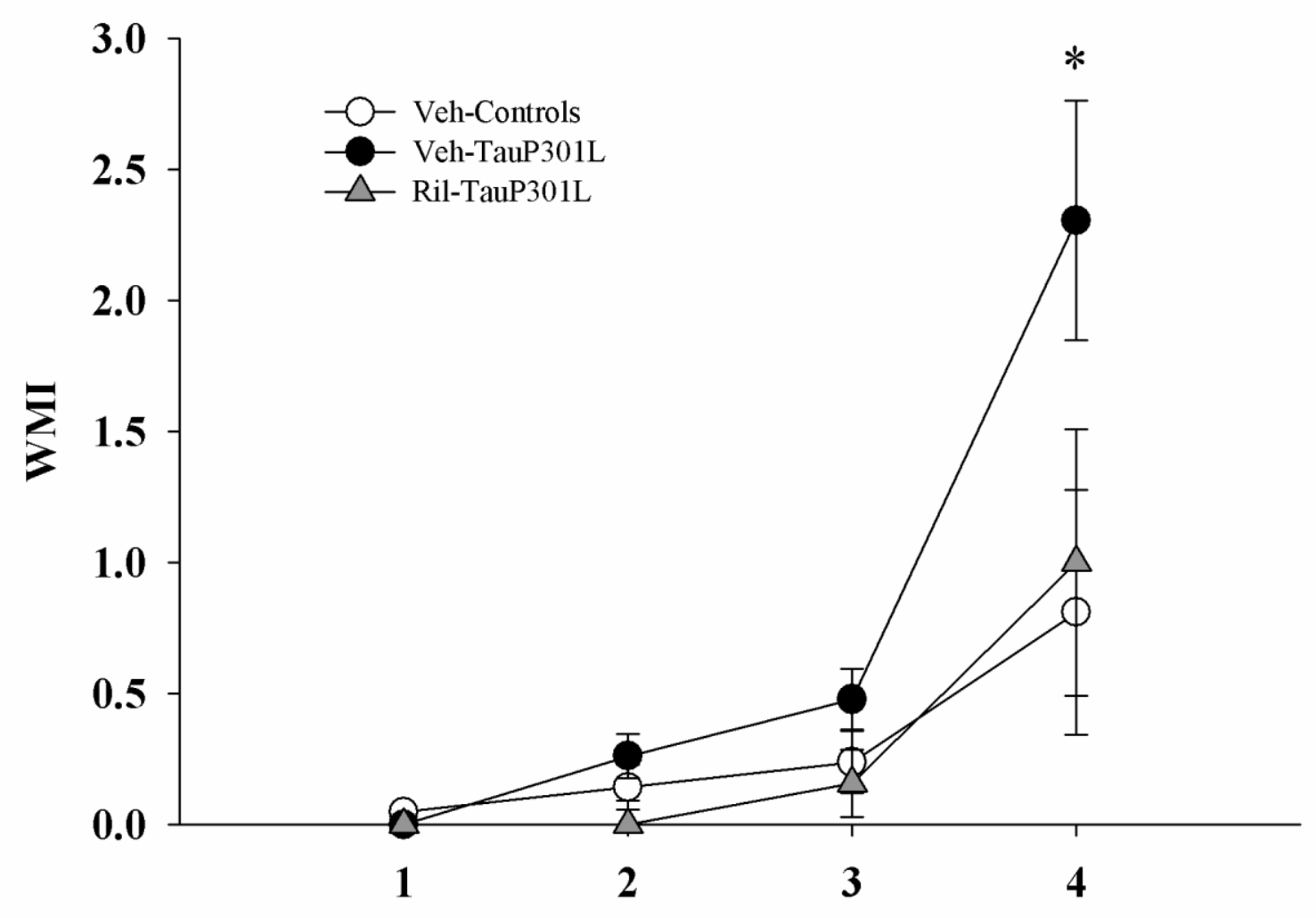

Trial

Figure 11. Veh-TauP301L mice show impaired memory performance at 7.5 months of age. On day 13, with the insertion of a 6-hour delay, Veh-TauP301L made significantly more WMI errors overall with increasing memory load. Ril-TauP301L mice made less errors than Veh-TauP301L mice; however, at the highest memory load, this difference was not significant. ${ }^{*} \mathrm{p}<.05$ VehControls vs. Veh-TauP301L). 


\section{Post-Tau: 5 and $7.5 \mathrm{M}$}

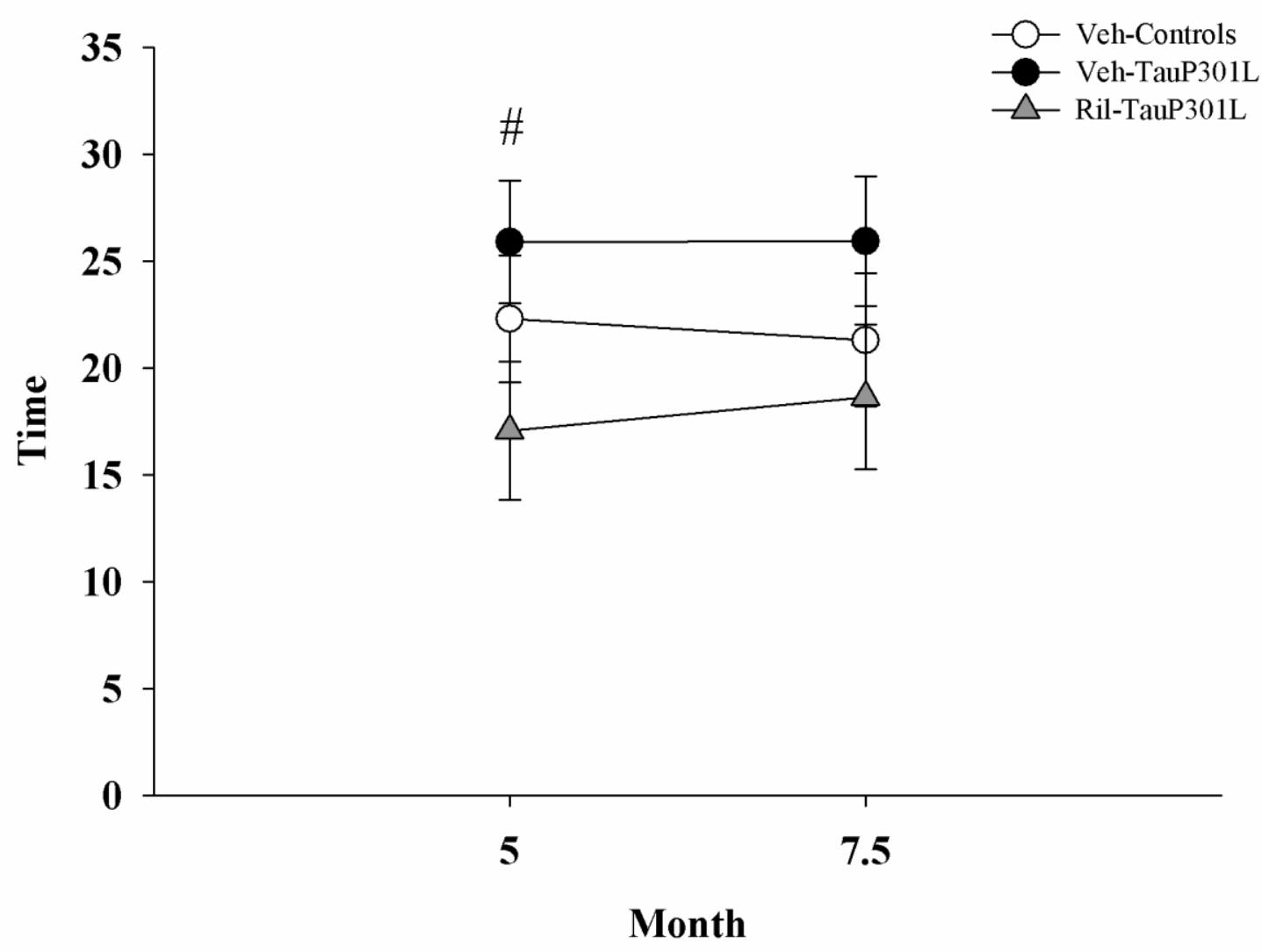

Figure 12. Veh-TauP301L mice take longer to locate the platforms at 5 and 7.5 months of age. A RMANOVA of trials following the 6-hour delay at 5 and 7.5 months of age showed that VehTauP301L took longer to find the platform in trials following the delay $(p=.02)$. (\# $\mathrm{p}<.05$ RilTauP301L vs Veh-TauP301L). 


\section{Post-Tau: 5 and 7.5 M}

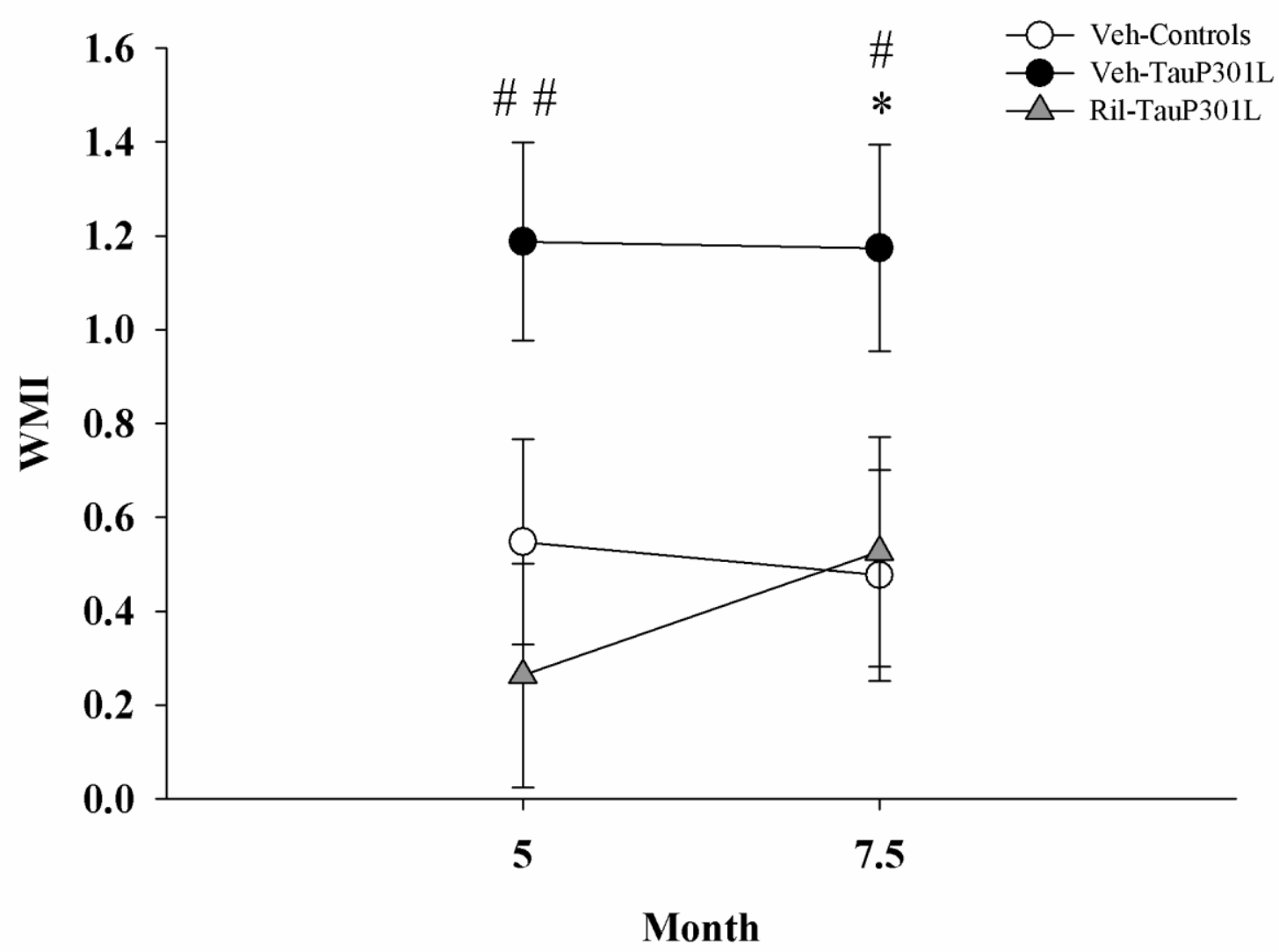

Figure 13. Riluzole rescues memory performance at 5 and 7.5 months of age. RMANOVA of trials following the 6-hour delay at 5 and 7.5 months showed that Veh-TauP301L made more WMI errors in trials following the delay, an effect rescued by the administration of riluzole ( $p$ $=.0009) .\left({ }^{*} \mathrm{p}<.05\right.$ Veh-Controls vs. Veh-TauP301L, \# $\mathrm{p}<.05$ Ril-TauP301L vs. Veh-TauP301L, \# \# p<.01 Ril-TauP301L vs. Veh-TauP301L). 
Abbreviations

\begin{tabular}{|l|l|}
\hline APOE-E4 & Apolipoprotein E type 4 \\
\hline APP & Amyloid precursor protein \\
\hline VGLUT & Vesicular glutamate transporter \\
\hline NMDAR & $N$-methyl-D-aspartate receptor \\
\hline S-NMDAR & Synaptic NMDAR \\
\hline E-NMDAR & Extra-synaptic NMDAR \\
\hline WRAM & Water radial arm maze \\
\hline WMC & Working memory correct error \\
\hline REF & Reference memory error \\
\hline WMI & Working memory incorrect error \\
\hline
\end{tabular}

Table 1. Abbreviations of terms used throughout the document. 
2.5 M Acquisition

\begin{tabular}{|c|c|c|c|c|}
\hline & \\
\hline & Time & WMC & WMI & REF \\
\hline Group & $\begin{array}{c}F(2,58)=1.27 \\
p=.29\end{array}$ & $\begin{array}{c}F(2,58)=0.46 \\
p=.64\end{array}$ & $\begin{array}{c}F(2,58)=0.15 \\
p=.86\end{array}$ & $\begin{array}{c}F(2,58)=0.19 \\
p=.83\end{array}$ \\
\hline Sex & $\begin{array}{c}F(1,58)=0.15 \\
p=.70\end{array}$ & $\begin{array}{c}F(1,58)=0.12 \\
p=.73\end{array}$ & $\begin{array}{c}F(1,58)=1.12 \\
p=.30\end{array}$ & $\begin{array}{c}F(1,58)=0.16 \\
p=.69\end{array}$ \\
\hline Group*Sex & $\begin{array}{c}F(2,58)=1.07 \\
p=.35\end{array}$ & $\begin{array}{c}F(2,58)=0.91 \\
p=.41\end{array}$ & $\begin{array}{c}F(2,58)=0.95 \\
p=.39\end{array}$ & $\begin{array}{c}F(2,58)=0.31 \\
p=.74\end{array}$ \\
\hline Day & $\begin{array}{c}F(9,522)=3.39 \\
p=.0005 * * *\end{array}$ & $\begin{array}{c}F(9,522)=3.33 \\
p=.0006 * * *\end{array}$ & $\begin{array}{c}F(9,522)=5.22 \\
p<.0001 * * *\end{array}$ & $\begin{array}{c}F(9,522)=8.74 \\
p<.0001 * * *\end{array}$ \\
\hline Day*Group & $\begin{array}{c}F(18,522)=1.17 \\
p=.28\end{array}$ & $\begin{array}{c}F(18,522)=0.89 \\
p=.60\end{array}$ & $\begin{array}{c}F(18,522)=1.01 \\
p=.45\end{array}$ & $\begin{array}{c}F(18,522)=0.81 \\
p=.69\end{array}$ \\
\hline Day*Sex & $\begin{array}{c}F(9,522)=2.00 \\
p=.04 *\end{array}$ & $\begin{array}{c}F(9,522)=1.14 \\
p=.33\end{array}$ & $\begin{array}{c}F(9,522)=1.01 \\
p=.43\end{array}$ & $\begin{array}{c}F(9,522)=1.45 \\
p=.16\end{array}$ \\
\hline $\begin{array}{l}\text { Day*Group } \\
\text { *Sex }\end{array}$ & $\begin{array}{c}F(18,522)=1.23 \\
p=.24\end{array}$ & $\begin{array}{c}F(18,522)=0.71 \\
p=.80\end{array}$ & $\begin{array}{c}F(18,522)=1.32 \\
p=.17\end{array}$ & $\begin{array}{c}F(18,522)=1.21 \\
p=.25\end{array}$ \\
\hline
\end{tabular}

Table 2. Acquisition. At 2.5 months of age, pre-tau expression, there were no Group differences in errors made for any error. There were significant Day effects for all errors $(p s>.001)$ and there was a significant Day*Sex interaction for time to find the platform during acquisition trials $(p<.05)$. 
2.5 M day 12 trials $1-4$

\begin{tabular}{|c|c|c|c|c|}
\hline & \\
\hline & Time & WMC & WMI & REF \\
\hline Group & $\begin{array}{c}F(2,58)=0.50 \\
p=.61\end{array}$ & $\begin{array}{c}F(2,58)=0.06 \\
p=.94\end{array}$ & $\begin{array}{c}F(2,58)=0.26 \\
p=.77\end{array}$ & $\begin{array}{c}F(2,58)=0.90 \\
p=.41\end{array}$ \\
\hline Sex & $\begin{array}{c}F(1,58)=0.20 \\
p=.66\end{array}$ & $\begin{array}{c}F(1,58)=0.00 \\
p=.94\end{array}$ & $\begin{array}{c}F(1,58)=3.96 \\
p=.05 *\end{array}$ & $\begin{array}{c}F(1,58)=1.19 \\
p=.28\end{array}$ \\
\hline Group*Sex & $\begin{array}{c}F(2,58)=0.76 \\
p=.47\end{array}$ & $\begin{array}{c}F(2,58)=1.03 \\
p=.36\end{array}$ & $\begin{array}{c}F(2,58)=0.01 \\
p=.99\end{array}$ & $\begin{array}{c}F(2,58)=0.04 \\
p=.97\end{array}$ \\
\hline Trial & $\begin{array}{c}F(3,174)=50.39 \\
p<.0001 * * *\end{array}$ & $\begin{array}{c}F(3,174)=55.63 \\
p<0.001 * * *\end{array}$ & $\begin{array}{c}F(3,174)=13.65 \\
p<0.001 * * *\end{array}$ & $\begin{array}{c}F(3,174)=20.59 \\
p<.0001 * * *\end{array}$ \\
\hline Trial*Group & $\begin{array}{c}F(6,174)=0.29 \\
p=.34\end{array}$ & $\begin{array}{c}F(6,174)=0.43 \\
p=.86\end{array}$ & $\begin{array}{c}F(6,174)=0.44 \\
p=.85\end{array}$ & $\begin{array}{c}F(6,174)=0.49 \\
p=.82\end{array}$ \\
\hline Trial*Sex & $\begin{array}{c}F(3,174)=0.67 \\
p=.57\end{array}$ & $\begin{array}{c}F(3,174)=0.50 \\
p=.68\end{array}$ & $\begin{array}{c}F(3,174)=1.50 \\
p=.22\end{array}$ & $\begin{array}{c}F(3,174)=1.89 \\
p=.13\end{array}$ \\
\hline $\begin{array}{l}\text { Trial*Group } \\
* \text { Sex }\end{array}$ & $\begin{array}{c}F(6,174)=0.63 \\
p=.70\end{array}$ & $\begin{array}{c}F(6,174)=0.40 \\
p=.88\end{array}$ & $\begin{array}{c}F(6,174)=0.30 \\
p=.94\end{array}$ & $\begin{array}{c}F(6,174)=0.82 \\
p=.56\end{array}$ \\
\hline
\end{tabular}

Table 3. Day 12, 4-hour delay. At 2.5 months of age, pre-tau expression, during the 4-hour delay, there were no Group differences in errors made for any dependent measure. There was a significant effect of Sex on WMI $(p<.05)$. Also, there were significant trial effects for all errors $(p \mathrm{~s}<.0001)$. 
5 M Acquisition

\begin{tabular}{|c|c|c|c|c|}
\hline & & & & \\
\hline & Time & WMC & WMI & REF \\
\hline Group & $\begin{array}{c}F(2,58)=0.25 \\
p=.78\end{array}$ & $\begin{array}{c}F(2,58)=0.82 \\
p=.44\end{array}$ & $\begin{array}{c}F(2,58)=1.19 \\
p=.31\end{array}$ & $\begin{array}{c}F(2,58)=2.26 \\
p=.11\end{array}$ \\
\hline Sex & $\begin{array}{c}F(1,58)=6.03 \\
p=.02 *\end{array}$ & $\begin{array}{c}F(1,58)=4.21 \\
p=.04^{*}\end{array}$ & $\begin{array}{c}F(1,58)=5.10 \\
p=.03 *\end{array}$ & $\begin{array}{c}F(1,58)=5.90 \\
p=.02 *\end{array}$ \\
\hline Group*Sex & $\begin{array}{c}F(2,58)=1.14 \\
p=.33\end{array}$ & $\begin{array}{c}F(2,58)=1.18 \\
p=.31\end{array}$ & $\begin{array}{c}F(2,58)=0.25 \\
p=.78\end{array}$ & $\begin{array}{c}F(2,58)=0.21 \\
p=.81\end{array}$ \\
\hline Day & $\begin{array}{c}F(9,522)=6.33 \\
p<.0001 * * *\end{array}$ & $\begin{array}{c}F(9,522)=1.05 \\
p=.40\end{array}$ & $\begin{array}{c}F(9,522)=6.65 \\
p<.0001 * * *\end{array}$ & $\begin{array}{c}F(9,522)=6.60 \\
p<.0001 * * *\end{array}$ \\
\hline Day*Group & $\begin{array}{c}F(18,522)=1.13 \\
p=.32\end{array}$ & $\begin{array}{c}F(18,522)=1.25 \\
p=.21\end{array}$ & $\begin{array}{c}F(18,522)=0.79 \\
p=.71\end{array}$ & $\begin{array}{c}F(18,522)=1.77 \\
p=.03 *\end{array}$ \\
\hline Day*Sex & $\begin{array}{c}F(9,522)=0.72 \\
p=.69\end{array}$ & $\begin{array}{c}F(9,522)=1.05 \\
p=.40\end{array}$ & $\begin{array}{c}F(9,522)=0.22 \\
p=.99\end{array}$ & $\begin{array}{c}F(9,522)=0.88 \\
p=.54\end{array}$ \\
\hline $\begin{array}{l}\text { Day*Group } \\
\text { *Sex }\end{array}$ & $\begin{array}{c}F(18,522)=0.94 \\
p=.52\end{array}$ & $\begin{array}{c}F(18,522)=1.11 \\
p=.34\end{array}$ & $\begin{array}{c}F(18,522)=0.78 \\
p=.72\end{array}$ & $\begin{array}{c}F(18,522)=0.73 \\
p=.78\end{array}$ \\
\hline
\end{tabular}

Table 4. Acquisition. At 5 months of age, 2.5 months post-tau expression, there was no Day effect for WMC $(p>.10)$; however, there were effects of Day for time, WMI, and REF ( $p$ s $>.0001)$. There were significant effects of Sex for all errors $(p \mathrm{~s}<.05)$. There was also a significant Day*Group effect where Veh-Controls initially made more REF errors but improved with training, whereas Veh-TauP301L mice did not improve with additional training $(p=.03)$. 
7.5 M Acquisition

\begin{tabular}{|c|c|c|c|c|}
\hline & Time & WMC & WMI & REF \\
\hline Group & $\begin{array}{c}F(2,57)=0.66 \\
p=.52\end{array}$ & $\begin{array}{c}F(2,57)=1.02 \\
p=.37\end{array}$ & $\begin{array}{c}F(2,57)=1.10 \\
p=.34\end{array}$ & $\begin{array}{c}F(2,57)=0.09 \\
p=.92\end{array}$ \\
\hline Sex & $\begin{array}{c}F(1,57)=0.18 \\
p=.67\end{array}$ & $\begin{array}{c}F(1,57)=0.33 \\
p=.57\end{array}$ & $\begin{array}{c}F(1,57)=0.05 \\
p=.82\end{array}$ & $\begin{array}{c}F(1,57)=0.96 \\
p=.33\end{array}$ \\
\hline Group*Sex & $\begin{array}{c}F(2,57)=0.27 \\
p=.76\end{array}$ & $\begin{array}{c}F(2,57)=0.57 \\
p=.57\end{array}$ & $\begin{array}{c}F(2,57)=0.38 \\
p=.68\end{array}$ & $\begin{array}{c}F(2,57)=0.56 \\
p=.57\end{array}$ \\
\hline Day & $\begin{array}{c}F(9,513)=9.72 \\
p<.0001 * * *\end{array}$ & $\begin{array}{c}F(9,513)=4.08 \\
p<.0001 * * *\end{array}$ & $\begin{array}{c}F(9,513)=9.25 \\
p<.0001 * * *\end{array}$ & $\begin{array}{c}F(9,513)=5.96 \\
p<.0001 * * *\end{array}$ \\
\hline Day*Group & $\begin{array}{c}F(18,513)=0.70 \\
p=.82\end{array}$ & $\begin{array}{c}F(18,513)=1.04 \\
p=.42\end{array}$ & $\begin{array}{c}F(18,513)=0.97 \\
p=.50\end{array}$ & $\begin{array}{c}F(18,513)=1.27 \\
p=.21\end{array}$ \\
\hline Day*Sex & $\begin{array}{c}F(9,513)=0.30 \\
p=.97\end{array}$ & $\begin{array}{c}F(9,513)=0.29 \\
p=.98\end{array}$ & $\begin{array}{c}F(9,513)=0.41 \\
p=.93\end{array}$ & $\begin{array}{c}F(9,513)=0.74 \\
p=.68\end{array}$ \\
\hline $\begin{array}{l}\text { Day*Group } \\
\text { *Sex }\end{array}$ & $\begin{array}{c}F(18,513)=1.24 \\
p=.22\end{array}$ & $\begin{array}{c}F(18,513)=1.19 \\
p=.27\end{array}$ & $\begin{array}{c}F(18,513)=0.93 \\
p=.54\end{array}$ & $\begin{array}{c}F(18,513)=0.97 \\
p=.49\end{array}$ \\
\hline
\end{tabular}

Table 5. Acquisition. At 7.5 months of age, 5 months post-tau expression, no effects of Group, Sex, or Group*Sex interactions were observed on any error $(p s>.10)$. There were significant effects of day for all errors $(p s<.0001)$. 
$5 \mathrm{M}$ day 12 trials 1-4

\begin{tabular}{|c|c|c|c|c|}
\hline & \\
\hline & Time & WMC & WMI & REF \\
\hline Group & $\begin{array}{c}F(2,58)=0.10 \\
p=.91\end{array}$ & $\begin{array}{c}F(2,58)=0.78 \\
p=.46\end{array}$ & $\begin{array}{c}F(2,58)=1.36 \\
p=.26\end{array}$ & $\begin{array}{c}F(2,58)=0.87 \\
p=.43\end{array}$ \\
\hline Sex & $\begin{array}{c}F(1,58)=1.42 \\
p=.24\end{array}$ & $\begin{array}{c}F(1,58)=1.66 \\
p=.20\end{array}$ & $\begin{array}{c}F(1,58)=0.40 \\
p=.53\end{array}$ & $\begin{array}{c}F(1,58)=0.81 \\
p=.37\end{array}$ \\
\hline Group*Sex & $\begin{array}{c}F(2,58)=0.31 \\
p=.73\end{array}$ & $\begin{array}{c}F(2,58)=1.60 \\
p=.21\end{array}$ & $\begin{array}{c}F(2,58)=0.83 \\
p=.44\end{array}$ & $\begin{array}{c}F(2,58)=0.10 \\
p=.90\end{array}$ \\
\hline Trial & $\begin{array}{c}F(3,174)=33.31 \\
p<.0001 * * *\end{array}$ & $\begin{array}{c}F(3,174)=42.53 \\
p<.0001 * * *\end{array}$ & $\begin{array}{c}F(3,174)=12.57 \\
p<.0001 * * *\end{array}$ & $\begin{array}{c}F(3,174)=2.65 \\
p=.05 *\end{array}$ \\
\hline Trial*Group & $\begin{array}{c}F(6,174)=0.77 \\
p=.60\end{array}$ & $\begin{array}{c}F(6,174)=0.74 \\
p=.62\end{array}$ & $\begin{array}{c}F(6,174)=1.08 \\
p=.37\end{array}$ & $\begin{array}{c}F(6,174)=2.11 \\
p=.05\end{array}$ \\
\hline Trial*Sex & $\begin{array}{c}F(3,174)=0.67 \\
p=.57\end{array}$ & $\begin{array}{c}F(3,174)=1.09 \\
p=.36\end{array}$ & $\begin{array}{c}F(3,174)=0.30 \\
p=.82\end{array}$ & $\begin{array}{c}F(3,174)=2.24 \\
p=.09\end{array}$ \\
\hline $\begin{array}{l}\text { Trial*Group } \\
* \text { Sex }\end{array}$ & $\begin{array}{c}F(6,174) 0.72 \\
p=.63\end{array}$ & $\begin{array}{c}F(6,174)=0.65 \\
p=.69\end{array}$ & $\begin{array}{c}F(6,174)=0.36 \\
p=.90\end{array}$ & $\begin{array}{c}F(6,174)=0.82 \\
p=.56\end{array}$ \\
\hline
\end{tabular}

Table 6. Day 12, 4-hour delay. At 5 months of age, 2.5 months post-tau expression, there were no significant Group, Sex, or Group*Sex effects $(p s>.10)$. There were effects of Trial for time $(p<.0001)$, WMC $(p<.0001)$, WMI $(p s<.0001)$, and REF errors $(p=.05)$. 
5 M day 13 Trials 1-4

\begin{tabular}{|c|c|c|c|c|}
\hline & \\
\hline & Time & WMC & WMI & REF \\
\hline Group & $\begin{array}{c}F(2,58)=1.86 \\
p=.16\end{array}$ & $\begin{array}{c}F(2,58)=0.90 \\
p=.41\end{array}$ & $\begin{array}{c}F(2,58)=5.49 \\
p=0.007 * *\end{array}$ & $\begin{array}{c}F(2,58)=1.89 \\
p=.16\end{array}$ \\
\hline Sex & $\begin{array}{c}F(1,58)=2.63 \\
p=.11\end{array}$ & $\begin{array}{c}F(1,58)=1.50 \\
p=.23\end{array}$ & $\begin{array}{c}F(1,58)=1.00 \\
p=.32\end{array}$ & $\begin{array}{c}F(1,58)=0.25 \\
p=.62\end{array}$ \\
\hline Group*Sex & $\begin{array}{c}F(2,58)=0.28 \\
p=.75\end{array}$ & $\begin{array}{c}F(2,58)=0.01 \\
p=.99\end{array}$ & $\begin{array}{c}F(2,58)=2.31 \\
p=.11\end{array}$ & $\begin{array}{c}F(2,58)=1.14 \\
p=.32\end{array}$ \\
\hline Trial & $\begin{array}{c}F(3,174)=31.15 \\
p<.0001 * * *\end{array}$ & $\begin{array}{c}F(3,174)=38.91 \\
p<.0001 * * *\end{array}$ & $\begin{array}{c}F(3,174)=10.76 \\
p<.0001 * * *\end{array}$ & $\begin{array}{c}F(3,174)=6.31 \\
p=.0004 * * *\end{array}$ \\
\hline Trial*Group & $\begin{array}{c}F(6,174)=1.71 \\
p=.12\end{array}$ & $\begin{array}{c}F(6,174)=1.57 \\
p=.16\end{array}$ & $\begin{array}{c}F(6,174)=1.96 \\
p=.07\end{array}$ & $\begin{array}{c}F(6,174)=1.68 \\
p=.13\end{array}$ \\
\hline Trial*Sex & $\begin{array}{c}F(3,174)=0.96 \\
p=.41\end{array}$ & $\begin{array}{c}F(3,174)=1.15 \\
p=.33\end{array}$ & $\begin{array}{c}F(3,174)=0.20 \\
p=.90\end{array}$ & $\begin{array}{c}F(3,174)=0.69 \\
p=.52\end{array}$ \\
\hline $\begin{array}{l}\text { Trial*Group } \\
\text { *Sex }\end{array}$ & $\begin{array}{c}F(6,174)=0.21 \\
p=.97\end{array}$ & $\begin{array}{c}F(6,174)=0.10 \\
p>.99\end{array}$ & $\begin{array}{c}F(6,174)=0.56 \\
p=.76\end{array}$ & $\begin{array}{c}F(6,174)=0.64 \\
p=.70\end{array}$ \\
\hline
\end{tabular}

Table 7. Day 13, 6-hour delay. On day 13, at 5 months of age, Veh-TauP301L made more WMI errors. No other effects of Group, Sex, or Group*Sex interactions were observed ( $p$ s $>.05)$.

There were effects of Trial for time $(p<.0001)$, WMC $(p<.0001)$, WMI $(p<.0001)$, and REF errors $(p=.0004)$. 
7.5 M day 12 trials 1-4

\begin{tabular}{|c|c|c|c|c|}
\hline & & & & \\
\hline & Time & WMC & WMI & REF \\
\hline Group & $\begin{array}{c}F(2,57)=2.11, \\
p=.13\end{array}$ & $\begin{array}{c}F(2,57)=1.13, \\
p=.33\end{array}$ & $\begin{array}{c}F(2,57)=2.09 \\
p=.13\end{array}$ & $\begin{array}{c}F(2,57)=4.72 \\
p=.01 *\end{array}$ \\
\hline Sex & $\begin{array}{c}F(1,57)=0.56 \\
p=.46\end{array}$ & $\begin{array}{c}F(1,57)=0.57 \\
p=.45\end{array}$ & $\begin{array}{c}F(1,57)=0.04 \\
p=.84\end{array}$ & $\begin{array}{c}F(1,57)=0.08 \\
p=.77\end{array}$ \\
\hline Group*Sex & $\begin{array}{c}F(2,57)=1.17 \\
p=.32\end{array}$ & $\begin{array}{c}F(2,57)=1.41 \\
p=.25\end{array}$ & $\begin{array}{c}F(2,57)=1.55 \\
p=.22\end{array}$ & $\begin{array}{c}F(2,57)=1.50 \\
p=.23\end{array}$ \\
\hline Trial & $\begin{array}{c}F(3,171)=33.79 \\
p<.0001 * * *\end{array}$ & $\begin{array}{c}F(3,171)=39.98 \\
p<.0001 * * *\end{array}$ & $\begin{array}{c}F(3,171)=16.18 \\
p<.0001 * * *\end{array}$ & $\begin{array}{c}F(3,171)=4.33 \\
p=.006 * *\end{array}$ \\
\hline Trial*Group & $\begin{array}{c}F(6,171)=1.10 \\
p=.36\end{array}$ & $\begin{array}{c}F(6,171)=1.00 \\
p=.43\end{array}$ & $\begin{array}{c}F(6,171)=1.51 \\
p=.18\end{array}$ & $\begin{array}{c}F(6,171)=0.93 \\
p=.47\end{array}$ \\
\hline Trial*Sex & $\begin{array}{c}F(3,171)=0.13 \\
p=.94\end{array}$ & $\begin{array}{c}F(3,171)=.48 \\
p=.70\end{array}$ & $\begin{array}{c}F(3,171)=0.56 \\
p=.64\end{array}$ & $\begin{array}{c}F(3,171)=1.64 \\
p=.18\end{array}$ \\
\hline $\begin{array}{l}\text { Trial*Group } \\
\text { *Sex }\end{array}$ & $\begin{array}{c}F(6,171)=0.79 \\
p=.58\end{array}$ & $\begin{array}{c}F(6,171)=.75, p \\
=.61\end{array}$ & $\begin{array}{c}F(6,171)=1.38, p \\
=.23\end{array}$ & $\begin{array}{c}F(6,171)=0.72, p \\
=.64\end{array}$ \\
\hline
\end{tabular}

Table 8. Day 12, 6-hour delay. At 7.5 months of age, 5 months post-tau expression, VehTauP301L mice made more REF errors. No other effects of Group, Sex, or Group*Sex interactions were observed $(p s>.10)$ There were significant effects of Trial for time $(p<.0001)$, WMC $(p<.0001)$, WMI, $(p<.0001)$, and REF errors $(p=.006)$. 
7.5 M day 13 Trials $1-4$

\begin{tabular}{|c|c|c|c|c|}
\hline & \\
\hline & Time & WMC & WMI & REF \\
\hline Group & $\begin{array}{c}F(2,57)=2.42 \\
p=.10\end{array}$ & $\begin{array}{c}F(2,57)=1.99 \\
p=.15\end{array}$ & $\begin{array}{c}F(2,57)=4.27 \\
p=.02 *\end{array}$ & $\begin{array}{c}F(2,57)=2.38 \\
p=.10\end{array}$ \\
\hline Sex & $\begin{array}{c}F(1,57)=0.69 \\
p=.41\end{array}$ & $\begin{array}{c}F(1,57)=0.24 \\
p=.63\end{array}$ & $\begin{array}{c}F(1,57)=0.03 \\
p=.85\end{array}$ & $\begin{array}{c}F(1,57)=0.29 \\
p=.60\end{array}$ \\
\hline Group*Sex & $\begin{array}{c}F(2,57)=0.92 \\
p=.41\end{array}$ & $\begin{array}{c}F(2,57)=1.24 \\
p=.30\end{array}$ & $\begin{array}{c}F(2,57)=0.12 \\
p=.89\end{array}$ & $\begin{array}{c}F(2,57)=0.99 \\
p=.38\end{array}$ \\
\hline Trial & $\begin{array}{c}F(3,171)=42.12 \\
p<.0001 * * *\end{array}$ & $\begin{array}{c}F(3,171)=48.10 \\
p<.0001 * * *\end{array}$ & $\begin{array}{c}F(3,171)=18.92 \\
p<.0001 * * *\end{array}$ & $\begin{array}{c}F(3,171)=10.11, \\
p<.0001 * * *\end{array}$ \\
\hline Trial*Group & $\begin{array}{c}F(6,171)=1.91 \\
p=.08\end{array}$ & $\begin{array}{c}F(6,171)=1.82 \\
p=.10\end{array}$ & $\begin{array}{c}F(6,171)=2.68 \\
p=.02 *\end{array}$ & $\begin{array}{c}F(6,171)=0.74 \\
p=.62\end{array}$ \\
\hline Trial*Sex & $\begin{array}{c}F(3,171)=0.30 \\
p=.82\end{array}$ & $\begin{array}{c}F(3,171)=.0 .74 \\
p=.53\end{array}$ & $\begin{array}{c}F(3,171)=0.25 \\
p=.86\end{array}$ & $\begin{array}{c}F(3,171)=0.22 \\
p=.82\end{array}$ \\
\hline $\begin{array}{l}\text { Trial*Group } \\
* \text { Sex }\end{array}$ & $\begin{array}{c}F(6,171)=0.54 \\
p=.78\end{array}$ & $\begin{array}{c}F(6,171)=0.79 \\
p=.58\end{array}$ & $\begin{array}{c}F(6,171)=0.26 \\
p=.95\end{array}$ & $\begin{array}{c}F(6,171)=0.15 \\
p=.99\end{array}$ \\
\hline
\end{tabular}

Table 9. Day 13, 6-hour delay. On Day 13, at 7.5 months of age, Veh-TauP301L mice made more WMI errors as trials increased $(p=.02)$. No effects of Group, Sex, or Sex*Group interactions were observed for time, WMC, or REF errors ( $p \mathrm{~s}>.05)$. 
5 and 7.5 M - Day 13; 6-hour delay

\begin{tabular}{|l|c|c|c|c|}
\cline { 2 - 5 } \multicolumn{1}{c|}{} & Time & WMC & WMI & REF \\
\hline Group & $\boldsymbol{F ( 2 , 5 7 ) = \mathbf { 4 . 0 2 } ,}$ & $F(2,57)=2.29$, & $\boldsymbol{F}(\mathbf{2 , 5 7})=\mathbf{7 . 9 6}$, & $F(2,57)=0.46$, \\
$\boldsymbol{p}=\mathbf{0 0 0 9} * *$ & $p=.63$ \\
\hline Sex & $F(1,57)=1.56$, & $F(1,57)=1.45$, & $F(1,57)=0.00$, & $F(1,57)=0.87$, \\
& $p=.22$ & $p=.23$ & $p=.93$ & $p=.36$ \\
\hline & $F(2,57)=1.10$, & $F(2,57)=0.71$, & $F(2,57)=0.83$, & $F(2,57)=1.94$, \\
Group*Sex & $p=.33$ & $p=.50$ & $p=.44$ & $p=.15$ \\
\hline & $F(1,57)=0.00$, & $F(1,57)=0.20$, & $F(1,57)=0.30$, & $F(1,57)=0.30$, \\
Day & $p=.99$ & $p=.66$ & $p=.59$ & $p=.59$ \\
\hline & $F(2,57)=0.04$, & $F(2,57)=0.00$, & $F(2,57)=0.26$, & $F(2,57)=0.73$, \\
Day*Group & $p=.96$ & $p>.99$ & $p=.77$ & $p=.49$ \\
\hline & $F(1,57)=0.45$, & $F(1,57)=0.36$, & $F(2,57)=0.90$, & $F(1,57)=0.02$, \\
Day*Sex & $p=.50$ & $p=.55$ & $p=.35$ & $p=.90$ \\
\hline Day*Group & $F(2,57)=0.07$, & $F(2,57)=0.16$, & $F(2,57)=0.62$, & $F(2,57)=0.22$, \\
*Sex & $p=.93$ & $p=.85$ & $p=.54$ & $p=.80$ \\
\hline
\end{tabular}

Table 10. Day 13, 6 hour delay at 5 and 7.5 months of age. A RMANOVA revealed that VehTauP301L mice took more time to find the platform and made more WMI errors at 5 and 7.5 months of age. No other effects of Group, Sex, or Group*Sex interactions were observed ( $p$ s $>.05)$. 
Visible Platform Test

\begin{tabular}{|c|c|c|c|}
\cline { 2 - 4 } \multicolumn{1}{c|}{} & Group & Sex & Group*Sex \\
\hline \multirow{3}{*}{ Time } & $F(2,57)=2.10$, & $F(1,57)=0.80$, & $F(2,57)=2.63$, \\
& $p=.13$ & $p=0.37$ & $p=.08$ \\
\hline
\end{tabular}

Table 11. Visible Platform Test. There were no differences in time to find the visible platform $(p s>.05)$ at the conclusion of behavioral testing. 